\title{
The Climatological Impact of Recurving North Atlantic Tropical Cyclones on Downstream Extreme Precipitation Events 0
}

\author{
ROMAN POHORSKY \\ Institute of Geography, and Oeschger Centre for Climate Change Research, University of Bern, Bern, Switzerland \\ MATTHIAS RÖTHLISBERGER \\ Institute of Geography, and Oeschger Centre for Climate Change Research, University of Bern, Bern, and Institute
} for Atmospheric and Climate Science, ETH Zurich, Zurich, Switzerland

\section{CHRISTIAN M. GRAMS}

Institute for Atmospheric and Climate Science, ETH Zurich, Zurich, Switzerland, and Institute of Meteorology and Climate Research (IMK-TRO), Karlsruhe Institute of Technology, Karlsruhe, Germany

\section{JACOPO RIBOLDI}

Institute for Atmospheric and Climate Science, ETH Zurich, Zurich, Switzerland, and Laboratoire de Météorologie Dynamique/IPSL, École Normale Superiéure, PSL Research University, CNRS, Paris, France

\section{Olivia MARTIUS}

Institute of Geography, and Oeschger Centre for Climate Change Research, and Mobiliar Lab for Natural Risks, University of Bern, Bern, Switzerland

(Manuscript received 31 May 2018, in final form 8 February 2019)

\begin{abstract}
This study provides the first climatological assessment of the impact of recurving North Atlantic tropical cyclones (TCs) on downstream precipitation extremes. The response is evaluated based on time-lagged composites for 146 recurving TCs between 1979 and 2013 and quantified by the area affected by precipitation extremes (PEA) in a domain shifted relative to the TC-jet interaction location, which often encompasses major parts of Europe. The statistical significance of the PEA response to the TCs is determined using a novel bootstrapping technique based on flow analogs. A statistically significant increase in PEA is found between lags +42 and $+90 \mathrm{~h}$ after the TC-jet interaction, with a doubling of the PEA compared to analog cases without recurving TCs. A $K$-means clustering applied to the natural logarithm of potential vorticity fields $[\ln (\mathrm{PV})]$ around the TC-jet interaction points reveals four main flow configurations of North Atlantic TC-jet interactions. Two main mechanisms by which recurving TCs can foster precipitation extremes farther downstream emerge: 1) an "atmospheric river-like" mechanism, with anomalously high integrated vapor transport (IVT) downstream of the recurving TCs and 2) a "downstream-development" mechanism, with anomalously high IVT ahead of a downstream trough. Hereby, the analog bootstrapping technique separates the impact of the TC from that of the midlatitude flow's natural evolution on the PEA formation. This analysis reveals an unequivocal effect of the TCs for the atmospheric river-like cases, while for the downstream-development cases, a substantial increase in PEA is also found in the analogs without a TC.
\end{abstract}

Supplemental information related to this paper is available at the Journals Online website: https://doi.org/10.1175/MWR-D-180195.s1.

Corresponding author: Roman Pohorsky,pohorskyr@gmail.com

\section{Introduction}

When a tropical cyclone (TC) moves poleward it often recurves and can transform into an extratropical system in a process referred to as extratropical transition (ET). ET describes the chain of processes that occurs when a TC moves into a midlatitude environment characterized 
by increased baroclinicity and reduced sea surface temperatures and gradually transforms into an extratropical cyclone (Jones et al. 2003; Evans et al. 2017; Keller et al. 2019). In the North Atlantic $46 \%$ of all TCs recurve poleward into the midlatitudes (Hart and Evans 2001). Recent cases of recurving North Atlantic tropical cyclones (TCs) with devastating impact in North America or Europe (e.g., Hurricanes Katia in 2011, Sandy in 2012, and Ophelia in 2017) have brought the danger of TCs undergoing ET to the attention of a wider public. While these TCs are known for their severe direct impacts, less public and scientific attention has so far been paid to cases with potential for high-impact weather farther downstream, arising from the modification of the midlatitude large-scale circulation during ET.

The current state of knowledge on ET is summarized in two review papers focusing on the transitioning TC itself (Evans et al. 2017) and on the downstream impact of ET (Keller et al. 2019). As there is no generally accepted definition of ET many previous studies focused on the interaction of a recurving $\mathrm{TC}$ with the midlatitude flow. In the following we adopt this terminology and discuss TC recurvature instead of ET.

After a TC recurvature, the predictability of the downstream large-scale circulation can be strongly reduced, and operational numerical weather prediction models tend to have poorer forecast skill in the midlatitudes (Anwender et al. 2008; Grams et al. 2015; Aiyyer 2015; Quinting and Jones 2016). The reduction in predictability is related to difficulties in resolving the complex interaction of the recurving TC with the midlatitude upper-level waveguide (Keller et al. 2011; Grams et al. 2013; Keller et al. 2014). Ascending air in the recurving TC and enhanced moisture transport impinging on the midlatitude baroclinic zone causes strong latent heat release (e.g., Cordeira et al. 2013). The consequent lowPV (potential vorticity) air injection into the upper troposphere near the midlatitude waveguide can cause a jet acceleration and downstream ridge building (e.g., Atallah and Bosart 2003; Grams and Archambault 2016). Hence, a TC-jet interaction can be associated with the initiation (e.g., Riemer et al. 2008; Röthlisberger et al. 2016a; Riboldi et al. 2018) or amplification of a Rossby wave packet that disperses downstream and modifies the large-scale flow pattern (e.g., Riemer and Jones 2010; Grams et al. 2013; Archambault et al. 2015). While several studies established that TC-jet interactions can amplify the upper-level midlatitude flow, climatological studies suggest some differences between ocean basins (e.g., Torn and Hakim 2015; Quinting and Jones 2016). For instance, Quinting and Jones (2016) showed that North Pacific and south Indian Ocean recurving TCs are indeed associated with a statistically significant increase in frequency and amplitude of Rossby wave packets downstream, whereas no significant signal was observed in the North Atlantic, where recurving TCs often interact with a preamplified flow. This is relevant as the meridional amplification of the extratropical flow over the Atlantic is important for the formation of extreme precipitation events over Europe (e.g., Massacand et al. 2001; Piaget et al. 2015; Röthlisberger et al. 2016b).

Several case studies have directly assessed the role of recurving TCs on extreme weather in downstream regions [see Harr and Archambault (2016) for an overview]. While the impact of North Pacific recurving TCs on extreme weather in North America is generally established, the impact of North Atlantic recurving TCs in Europe is less clear [see discussion in Keller et al. (2019)]. Still, some case studies suggest that North Atlantic recurving TCs alter the intensity and the track of downstream cyclones (AgustíPanareda et al. 2004; Grams et al. 2011; Pantillon et al. 2013; Hardy et al. 2017). In addition, Grams and Blumer (2015) attributed severe thunderstorms over central Europe to the amplification of a narrow trough and enhanced moisture transport downstream of the ET of Katia (2011). So far, only the preliminary (non-peer-reviewed) work by Pinto et al. (2001) provides climatological evidence for an effect of recurving North Atlantic TCs on precipitation extremes in Europe. They showed that 13 of the 30 most extreme precipitation events in northwestern Italy were related to North Atlantic recurving TCs. Such events are related to processes such as Rossby wave amplification and enhanced atmospheric water vapor transport from tropical to the extratropical regions following TC recurvature.

However, no study so far has assessed if recurving TCs systematically increase the occurrence of high-impact weather events in downstream regions [see the outlook of Keller et al. (2019)]. Here we address the question whether, in a climatological sense, North Atlantic recurving TCs cause a significant increase in extreme precipitation events over downstream regions that can include Europe. Moreover, we investigate how the effect of recurving TCs is modulated by the large-scale flow over the North Atlantic in which the TC interacts with the jet.

The paper is structured as follows. The datasets and the attribution methodology are described in section 2 . The main results are presented in section 3. Links to previous studies and sensitivities of the methodology are discussed in section 4 . The paper closes with a conclusion and outlook in section 5 .

\section{Data and methods}

\section{a. Datasets}

All atmospheric data fields stem from the European Centre for Medium-Range Weather Forecasts (ECMWF) 
interim reanalysis (ERA-Interim) dataset (Dee et al. 2011). We use 6 -hourly fields interpolated to a $1^{\circ}$ by $1^{\circ}$ longitude-latitude grid for the period 1979 to 2013. Ertel potential vorticity (PV) was calculated on model levels and then interpolated to isentropic surfaces. When looking at cases from different seasons it is important to bear in mind that both the tropopause and the isentropic surfaces shift vertically throughout the year. $\mathrm{PV}$ is therefore analyzed at different isentropes during each month, exactly as in Röthlisberger et al. (2018). Integrated vapor transport is calculated following Lavers et al. (2012):

$$
\mathrm{IVT}=\frac{1}{g} \sqrt{\left(\int_{p=1000}^{p=300} q u d p\right)^{2}+\left(\int_{p=1000}^{p=300} q v d p\right)^{2}},
$$

where $g$ is the acceleration on Earth due to gravity; $q$ is the specific humidity; and $u$ and $v$ are the zonal and meridional wind components, respectively, and depend on the pressure $p$. (IVT is expressed in $\mathrm{kg} \mathrm{m}^{-1} \mathrm{~s}^{-1}$.)

We use the International Best Track Archive for Climate Stewardship (IBTrACS) dataset to identify recurving TCs between 1979 and 2013 (Knapp et al. 2010). The recurvature definition is based on the prior work of Archambault et al. (2013). Recurvature is objectively identified as a zonal velocity change (from westward to eastward) of a northward-moving TC. In case of multiple recurvatures along the track, the last one occurring south of $45^{\circ} \mathrm{N}$ is considered. All TCs recurving south of $45^{\circ} \mathrm{N}$ are considered, yielding a total of 150 cases; however, 4 TCs were discarded for reasons outlined below.

\section{b. Identification of recurving tropical cyclones and their respective interaction points and times}

We first define an interaction point and a time of maximum interaction $\left(t_{\text {int }}\right)$ between each recurving TC and the midlatitude waveguide, employing a metric based on the PV advection by the irrotational wind proposed by Archambault et al. (2013). We assume that the irrotational wind in the TC outflow region is primarily attributable to the TC itself. Here, the metric is computed on isentropic surfaces as in Riboldi et al. (2018):

$$
\mathrm{PV}_{\mathrm{adv}}=-\mathbf{V}_{\chi} \leq \cdot \nabla_{\theta} \mathrm{PV},
$$

where $\mathbf{V}_{\chi}$ is the irrotational isentropic wind vector and $\nabla_{\theta} \mathrm{PV}$ represents the isentropic potential vorticity (PV) gradient. $\mathrm{PV}_{\mathrm{adv}}$ is generally negative in regions where the diabatic outflow related to the transitioning TC strongly impinges onto the midlatitude waveguide (Archambault et al. 2013). The PV advection is calculated on isentropic surfaces between 325 and $355 \mathrm{~K}$ with $5-\mathrm{K}$ increments and then averaged vertically (hereafter referred to as $\overline{\mathrm{PVadv}})$. In the $\overline{\mathrm{PV} a d v}$ field we identify the point of interaction as the minimum $\overline{\mathrm{PVadv}}$ value in a TC-relative box extending $15^{\circ} \mathrm{W}$ and $5^{\circ} \mathrm{E}$ and $15^{\circ} \mathrm{N}$ and $5^{\circ} \mathrm{S}$ from the TC center (black box in Fig. 1). A second box $\left(15^{\circ} \times 15^{\circ}\right.$, blue dashed in Fig. 1) centered on the interaction point is then defined and $\overline{\mathrm{PVadv}}$ is averaged within this smaller box to yield a measure of the strength of the interaction (denoted as $I$ hereafter). Here $I$ is more representative than the value of $\mathrm{PV}_{\mathrm{adv}}$ at a single grid point and we therefore use $I$ for determining $t_{\text {int }}$. The term $I$ is calculated for every 6-hourly time step from -48 to $+144 \mathrm{~h}$ relative to each recurvature time of the IBTrACS data. The minimum in the $I$ time series for each TC is taken as $t_{\text {int }}$. In cases where a TC is not available in the IBTrACS data for all time steps after $t_{\text {int }}+144 \mathrm{~h}$, the search box remains fixed at the last known location of the TC in the IBTrACS until $t_{\text {int }}+144 \mathrm{~h}$ is reached. Of the 150 cases we discarded three cases, Tropical Storm Marco (12 October 1990), Hurricanes Nate (11 September 2005), and Hanna (6 September 2008) as they shared the same interaction points as other nearby recurving TCs, and one case, Hurricane Alberto (24 August 2000), because the point of interaction at $74^{\circ} \mathrm{N}$ was located too far north for our analysis. The remaining 146 points of maximum interaction are located between $102^{\circ}$ and $23^{\circ} \mathrm{W}$ and $35^{\circ}$ to $66^{\circ} \mathrm{N}$ with a mean location of $63^{\circ} \mathrm{W}$ and $48^{\circ} \mathrm{N}$ (Fig. 2).

\section{c. Extreme precipitation}

This study considers ERA-Interim daily precipitation accumulations produced by short-term forecasts (i.e., a value at a given time represents the accumulated precipitation in the preceding $24 \mathrm{~h}$ ). Therefore, each 6-hourly field used here, has an 18-h overlap with its preceding and succeeding value. Thus, extremes occurring on consecutive time steps are not independent as they most likely represent the same event and statistical methods requiring independence of extremes cannot be applied. This method has the advantage to account for events that occur in a 24-h period over two different days, which would otherwise be lost if using consecutive daily accumulation periods. Extremes are defined as values exceeding the climatological 99th percentile of the respective monthly climatology at each grid point, which is computed from the total distribution of all daily precipitation accumulations, including dry days, with 6-hourly increments between 1979 and 2013. Note that for our analysis only the timing and not the magnitude of the precipitation extreme events is relevant. Previous studies have shown that, in the extratropics, the timing of precipitation extremes is well represented in the ERA-Interim dataset (e.g., Pfahl and Wernli 2012).

Binary fields indicating extreme events (" 1 ") and nonextreme events ("0") are produced for every 6-h 


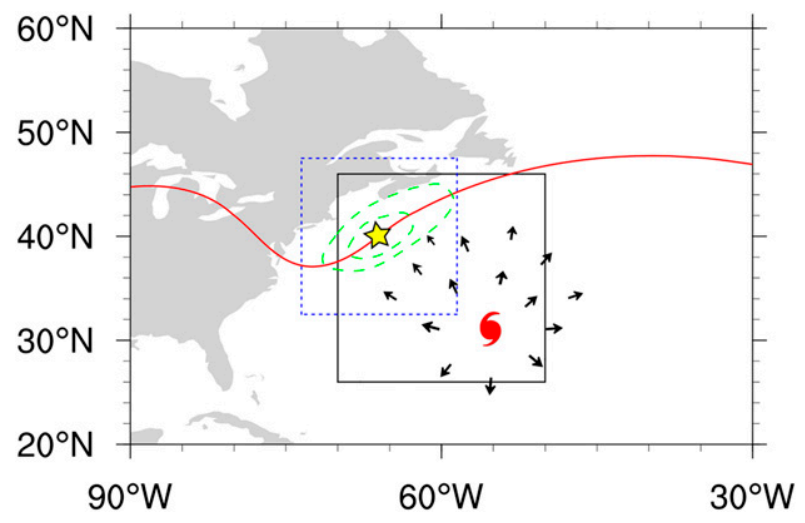

FIG. 1. Identification and characterization of a TC-jet interaction. The red line represents the isentropic 2-PVU contour collocated with the extratropical jet stream. The black box extending $15^{\circ}$ to the west, $5^{\circ}$ to the east, $15^{\circ}$ to the north, and $5^{\circ}$ to the south of the TC position is used to find the grid point of minimum $\overline{\mathrm{PVadv}}$, which represents the maximum interaction point (yellow star). A second box $\left(15^{\circ} \times 15^{\circ}\right.$, blue dashed) centered on the interaction point is then used to calculate the interaction strength $I$, by averaging

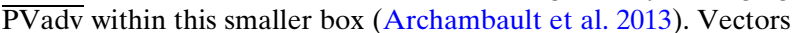
represent the irrotational wind component from the TC's outflow. Green dashed contours indicate regions of stronger negative PV advection near the waveguide.

time step. The precipitation extremes are then evaluated in a fixed domain relative to the point of maximum interaction, extending $60^{\circ}-83^{\circ}$ east of the interaction point and bounded meridionally between $35^{\circ}$ and $52^{\circ} \mathrm{N}$ (Fig. 2). This distance is motivated by the typical wavelength expected for the downstream Rossby wave packet. The region corresponds roughly to central Europe for TC-jet interaction points occurring near the mean location of all interaction points (Fig. 2). However, for each case, the domain is located over a different region, as we maintain the same zonal distance between the TCjet interaction point and the domain boundaries. This approach is motivated by the large case-to-case variability both in the interaction point location (Fig. 2) and the location of the expected downstream impacts. A sensitivity test confirmed that the results are robust with respect to slight (i.e., $\pm 5^{\circ}$ ) modifications of the domain size and location. As a consequence of the longitudinal variability of the interaction points, the domain can cover regions from the Atlantic to West Asia. An additional analysis of precipitation extremes in a nonmoving domain focused on Europe, (Fig. 2, bold rectangle) is presented in the online supplemental material (Figs. S1 and S3). Our main conclusions hold also for this conservative approach.

The precipitation extremes response to recurving TCs is quantified by the area fraction of this domain covered by extremes. This metric is hereafter referred to as precipitation extremes area (PEA) and is calculated for all TC-jet interaction events and for each 6-h time lag between 0 and $192 \mathrm{~h}$ after $t_{\text {int }}$.

\section{d. Analog bootstrapping}

The aim of the procedure outlined below is to assess whether or not temporal fluctuations of the PEA can be attributed to the TC-jet interaction. Recall that TC-jet interactions in the North Atlantic often occur during preamplified flow patterns (Quinting and Jones 2016), which even without a TC might be conducive to more widespread European precipitation extremes than climatology. Therefore, in order to attribute changes in the PEA to the recurving TCs, it is necessary to separate the effects of the preamplified flow from that of the recurving TCs.

The novel method proposed here accomplishes this by comparing actual TC-jet interaction cases with analog flow patterns. For every TC-jet interaction case we identify time steps with a similar upper-level flow in the vicinity of the interaction point but without a recurving

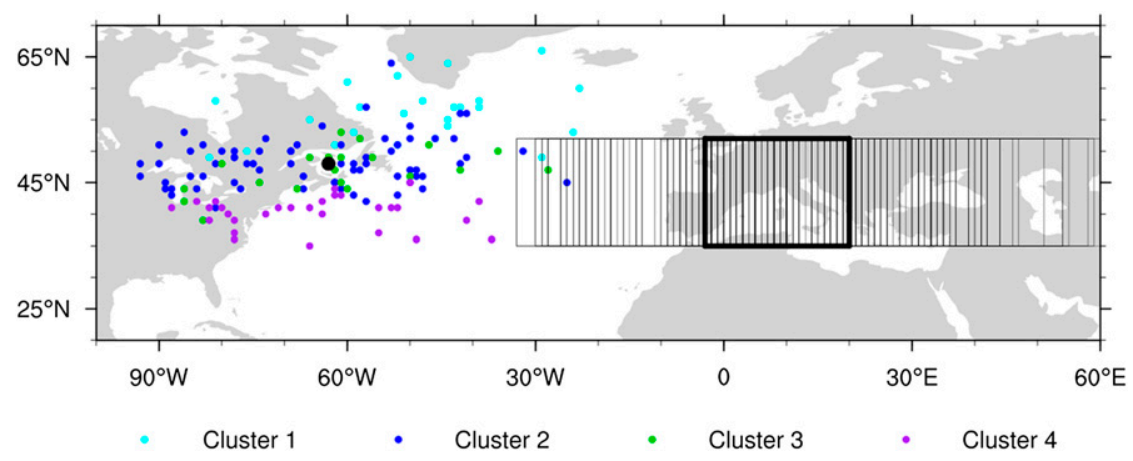

FIG. 2. All interaction points between recurving tropical cyclones and the extratropical waveguide (146 cases). The different colors indicate whether the respective interactions belong to cluster 1 (cyan, 21 cases), cluster 2 (blue, 68 cases), cluster 3 (green, 21 cases), or cluster 4 (purple, 31 cases). The superposed black rectangles indicate all the PEA domains relative to their respective interaction point. The black dot and bold black rectangle respectively represent the average interaction point and PEA domain location. 
(a)

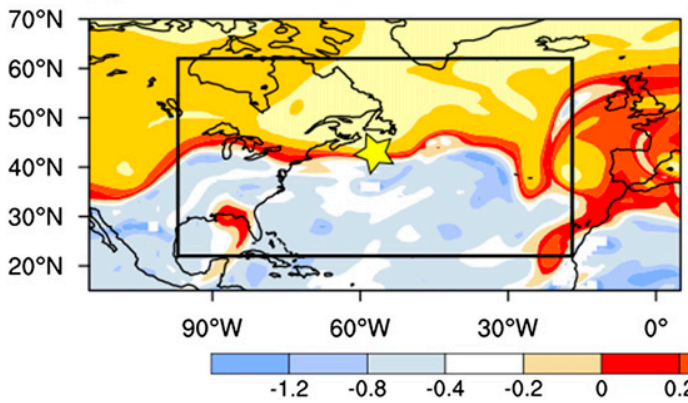

(b)

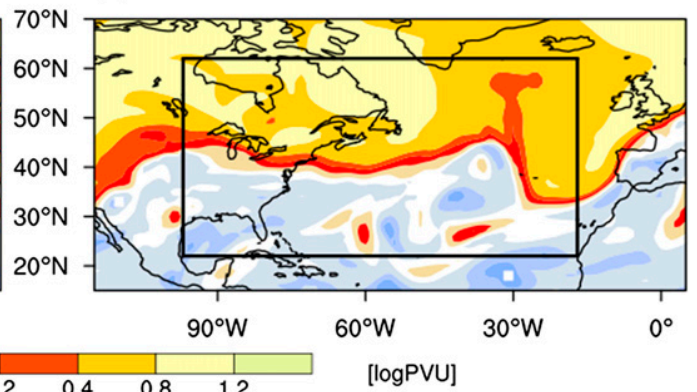

FIG. 3. (a) Example of a real-case TC-jet interaction on 30 Nov 1986 and (b) an analog flow pattern. The black rectangle in panel (a) extending $\pm 40^{\circ}$ from the point of maximum interaction (yellow star) in longitude and $\pm 20^{\circ}$ in latitude delimits the analog domain of the target $\ln (\mathrm{PV})$ field $\mathbf{x} . \ln (\mathrm{PV})$ fields $\mathbf{y}$ in the analog domain in $(\mathrm{b})$ are compared to the target field $\mathbf{x}$.

TC and consider those as analogs. By comparing the evolution of the atmospheric circulation after TC-jet interactions to analog cases, it becomes easier to isolate the effect of the TC from the natural evolution of the atmospheric flow.

Analogs could be chosen based on different variables, for example, geopotential height, upper-level winds, or $\mathrm{PV}$. Here we choose to use $\ln (\mathrm{PV})$ fields on month-specific isentropes [the same isentropes as in Röthlisberger et al. (2018)], because the $\ln (\mathrm{PV})$ field captures the large-scale flow geometry well and is tightly linked to the magnitude of the flow induced by PV anomalies (Martius et al. 2010).

For each TC-jet interaction, we first identify the target field (hereafter referred to as $\mathbf{x}$ ) as the $\ln (\mathrm{PV})$ field $48 \mathrm{~h}$ prior to $t_{\text {int }}$ in a domain extending $\pm 40^{\circ}$ in longitude and $\pm 20^{\circ}$ in latitude around the point of maximum interaction (hereafter referred to as analog domain, see black box in the example presented in Fig. 3). We define the targets $48 \mathrm{~h}$ prior to $t_{\text {int }}$ because we want to exclude the effects of the TC on the extratropical flow for the entire interaction period. The analog flow patterns to a given target field $\mathbf{x}$ are identified by searching for other time steps with a similar upper-level $\ln (\mathrm{PV})$ field in the analog domain $\mathbf{x}$ (Fig. 3). Similarity between the target $\boldsymbol{x}$ and candidates $\boldsymbol{y}$ is assessed by the Euclidean distance $D(\mathbf{x}, \mathbf{y})$ as

$$
D(\mathbf{x}, \mathbf{y})=\sqrt{\sum_{i=1}^{n}\left(x_{i}-y_{i}\right)^{2}}
$$

for all ERA-Interim time steps between 1979 and 2013. Here $n$ denotes the number of grid points in the analog domain and $x_{i}\left(y_{i}\right)$ is the $i$ th grid point of $\mathbf{x}(\mathbf{y})$, respectively. To avoid seasonality biases, we only consider candidates $\mathbf{y}$ from the same meteorological season as the target $\mathbf{x}$ [e.g., March-May (MAM), June-August (JJA), September-November (SON), December-February (DJF)].
Moreover, we exclude all candidates during which a TC-jet interaction occurs within \pm 7 days. This results in roughly 12000 candidate time steps for each TC-jet interaction case, from which we choose the 100 closest analogs as the candidates with the lowest $D$ values.

In a bootstrapping procedure we then construct 1000 sets of analogs to the real TC-jet interactions. For each set, we randomly choose one of the corresponding 100 analogs for each of the $146 \mathrm{TC}$-jet interaction cases. Then, analog time series of PEA are constructed exactly as for the real cases. For each analog, the same maximum interaction point coordinates as the real case it belongs to are used. Time lags at which the mean PEA across the 146 cases exceeds the 99th percentile of the analog sample of mean PEA values are considered as significant.

The analogs are further used to identify significant anomalies in upper-level PV and integrated vapor transport (IVT) between the studied cases and their analogs. For this purpose, the composite maps from the TC-jet interaction cases are compared to 1000 random composites constructed from the analogs. For each time step, the PV and IVT at each grid point within the TC-jet interaction composites are compared to the 1000 random composite distribution. If the values of the TC-jet interaction composite fall within the highest (lowest) percentiles (i.e., 99th and 1st percentile) of the analog sample distribution, the PV or IVT value is considered as statistically significantly different from the random analog composites.

\section{e. Clustering of North Atlantic TC-jet interactions}

The downstream effects of the TC-jet interactions are known to depend on the large-scale upper-level flow pattern over the Atlantic at the time of the transition (Agustí-Panareda et al. 2004, 2005; Agustí-Panareda 2008; McTaggart-Cowan et al. 2001, 2003, 2007). 
We therefore use a $K$-means cluster analysis to assess which upper-level flow configuration at the time of TCjet interaction is particularly conducive to increased downstream PEA. Visual analysis of approximately 40 cases suggested that four flow categories best represent this variability (Pohorsky 2017). These four categories of flow configurations during TC-jet interactions are identified objectively based on a $K$-means clustering technique (Wilks 2006, section 14.3.1) applied to $\ln (\mathrm{PV})$ fields around the respective points of maximum interaction. The field considered for each TC-jet interaction case is selected at $t_{\text {int }}$, with longitudinal boundaries at $-40^{\circ}$ to $+60^{\circ}$ longitude and latitudinal boundaries at $\pm 20^{\circ}$ latitude relative to the point of maximum interaction (hereafter referred to as clustering domain). Each grid point of the PV field is used as a dimension in space. As for the analog selection, the Euclidean distance [Eq. (3)] is used as a distance metric to measure the distance between each case and the clusters' centroids. The clustering procedure proceeds as follows. First, the initial centroids are randomly defined and the distance $D$ between each case and the four centroids is calculated. Each case is then attributed to its closest centroid. Once this operation is finished, new centroids are calculated as the gravity centers of each cluster. Then distances between each case and the four clusters are recalculated. If the distance between a case and a centroid from another cluster is smaller than the distance from its own centroid, the case is reattributed to the cluster of the closest centroid and the operation starts over. This operation is repeated until no reassignment needs to be done.

The clustering is repeated 100 times to identify the most stable cluster configuration (i.e., the most recurrent cluster configuration).

\section{f. Sensitivity to methodological choices}

The results presented below are based on statistical inferences and might be sensitive to the chosen methodology. Of critical importance is the choice of the analogs used to determine the statistical significance. (A comparison of the analog PV composites and the PV composites of all cases and of each cluster $48 \mathrm{~h}$ prior to the time of maximum interaction is presented in Figs. 5, $7,8,9$, and 10.) Overall the analog selection appears to work very well. At $t_{\text {int }}-48 \mathrm{~h}$ (time when the analogs are selected), there are no statistically significant difference in upper-level PV between the analogs and the TC recurvature cases for the entire sample and for all the cluster subsamples. Only in cluster 4 is the upstream trough slightly deeper in the TC recurvature cases compared to the analogs.
A second important parameter is the location and size of the PEA domain. The spatial aggregation of the extremes is necessary due to the variability in the location of the points of maximum interaction and the variability of the detailed structure of the upper-level flow. In the 146-case sample, very few grid points are affected more than once by precipitation extremes and an analysis based on extremes occurring at specific grid points is therefore not informative. We have tested the sensitivities of the results both to the exact location and size of the domain and found that our conclusions are robust with regard to these choices.

\section{Results}

\section{a. All recurvature events}

We first analyze precipitation extremes after all 146 recurvature events, regardless of the different initial flow configurations. The PEA in the considered domain (cf. section 2c) peaks at $2.1 \%$, which corresponds to a doubling of the PEA compared to analog cases, in a time window from 54 to $72 \mathrm{~h}$ after $t_{\text {int }}$ (Fig. 4a). A statistically significant increase in the PEA is found between 42 and $90 \mathrm{~h}$ after $t_{\text {int }}$ (red line outside the gray shading). The PEA derived from the analogs also increases slightly compared to the initial value at $t_{\text {int }}$, but this increase remains much more moderated, with a peak of $1.1 \%$ for the mean of the distribution at $84 \mathrm{~h}$ and $1.5 \%$ for the $99 \mathrm{th}$ percentile. Hence, when considering all cases of North Atlantic recurving tropical cyclones, the largest effects on precipitation extremes in the PEA domain is observed roughly 2-3 days after $t_{\text {int }}$. We note, however, that the case-to-case variability within each composite is much larger than the variance between the 1000 composite means. Figure $4 \mathrm{~b}$ shows the PEA spread (10th90th percentiles interval) among all 146 individual cases (red shading). Similarly, the gray shading indicates the PEA spread in the individual analogs (14600) used to create the bootstrapping samples. The large spread indicates that not all TC-jet interaction cases are followed by an increase in PEA but is also indicative of time differences between the different peaks in PEA among the cases triggering precipitation extremes (Fig. 4b). Despite this large spread, the 90th percentile of the distribution reaches values above 7\% PEA, while the 90th percentile of the analog's distribution reaches roughly $3 \%$ PEA, indicating that the most extreme PEA downstream of a recurving TC roughly doubles compared to the most extreme PEA of the analog cases (Fig. 4a).

We next focus on spatial composites of PV and IVT for all TC-jet interaction cases (Fig. 5). The composites are centered in longitude on the interaction points 
(a)

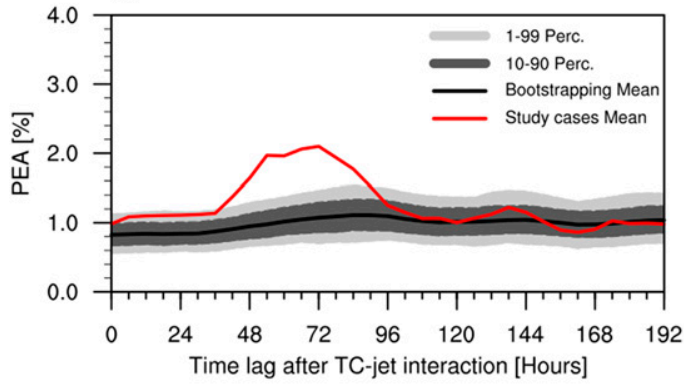

(b)

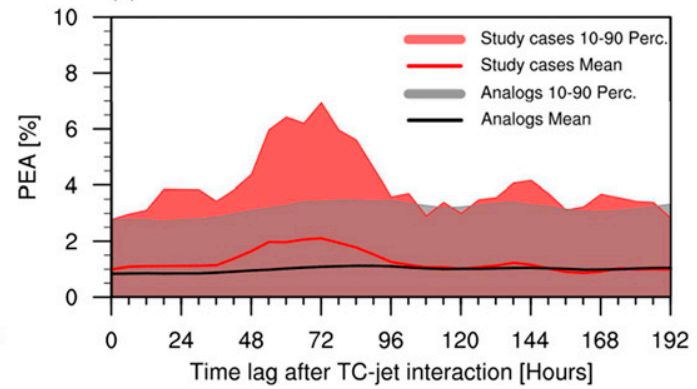

FIG. 4. (a) Averaged time evolution of the precipitation extremes area (PEA) in \% for all 146 cases (red). Dark and light gray bands indicate the 10th and 90th and the 1st and 99th percentile of the averaged 1000-member analog bootstrapping composites sample, respectively. The black line indicates the average of the 1000 analog composites. (b) Indication of the case-to-case variability of PEA within all cases. Red line indicates the average PEA as in (a). Reddish shading indicates the 10th and 90th percentile of the PEA distribution of the individual study cases. The black line indicates the average of all individual analog cases used for the bootstrapping in (a). Gray shading indicates the 10th and 90th percentile of all individual analog cases used for the bootstrapping.

(longitudes relative to the interaction points are hereafter referred to as lon*) and have a constant latitudinal range from $30^{\circ}$ to $70^{\circ} \mathrm{N}$. This choice is motivated by Earth's curvature, which would lead to inconsistencies in the zonal distance between the interaction point and the PEA domain if different latitude ranges were used when creating composites. Temporally, we composite with respect to $t_{\text {int }}$. Figure 5 shows PV and IVT anomalies where the composite mean value of all TC-jet interaction cases is statistically different from the analog samples distribution (values outside the 1st-99th interval). Two days before $t_{\text {int }}$, the composite PV should by construction not deviate significantly from the analogs in the area surrounding the maximum interaction point. This is indeed the case and can be interpreted as a quality check for the analog selection (Fig. 5a). In contrast, the composite IVT field does show significant deviations from the analogs $48 \mathrm{~h}$ prior to $t_{\mathrm{int}}$, in particular high IVT is present south of $35^{\circ} \mathrm{N}$ in the vicinity of the average TC location, as well as north of $50^{\circ} \mathrm{N}$ (Fig. 5b).

At $t_{\text {int }}$, a highly amplified trough-ridge $\left(\mathrm{T}_{1}-\mathrm{R}_{1}\right)$ couplet is extending from lon $*=-20^{\circ}$ to $+40^{\circ}$ (Fig. 5c). Comparing the average latitude of the waveguide shows that for the recurving TC composite, the trough $\left(\mathrm{T}_{1}\right)$ extends more than $5^{\circ}$ farther equatorward and the ridge $\mathrm{R}_{1}$ more than $5^{\circ}$ farther poleward compared to the analog composites (Fig. 5c). This is in agreement with earlier studies showing that transitioning TCs produce an amplification of the extratropical flow (e.g., Riemer and Jones 2010; Archambault et al. 2015). Farther downstream, between lon* $=+40^{\circ}$ and $+55^{\circ}$, a positive PV anomaly $\left(\mathrm{A}_{1}\right.$, Fig. $\left.5 \mathrm{c}\right)$ and a more southerly location of the jet indicates that a trough develops downstream, at least in some cases. At $t_{\text {int }}$, this downstream trough is located just west of the PEA domain, starting at lon* $=60^{\circ}$ east of the maximum interaction point (dashed boxes in Fig. 5) and amplifies until lag $+18 \mathrm{~h}$ (not shown). At $t_{\text {int }}$, an area of anomalously high IVT extends from $30^{\circ}$ to $65^{\circ} \mathrm{N}$ and approximately from lon* $=+0^{\circ}$ to lon* $=+20^{\circ}$ with a slight southwestnortheast tilt (Fig. 5d). This vigorous moisture transport is a signature of the transitioning TCs. The low IVT values upstream and within the trough (Fig. 5d) are conceivably a consequence of the combined effects of 1 ) the cyclonic circulation of the TC and 2) the far-field effect of the northerly flow at the western flank of the upper-level trough, advecting relatively dry air from the north. At lag $+48 \mathrm{~h}$, the PEA is significantly increased compared to the analog samples (Fig. 4). At the same time, the highly amplified ridge $R_{1}$ is extending between lon* $=+25^{\circ}$ and $+50^{\circ}$ (Fig. 5 e) and up to $10^{\circ}$ farther poleward than in the analog mean (Fig. 5e). However, no systematic anomalous equatorward extension of the tropopause is found downstream of ridge $\mathrm{R}_{1}$ (Figs. $5 \mathrm{c}, \mathrm{e}$ ). This is conceivably due to case-to-case variability of both the wavelength and amplitude of the ridge and the downstream trough.

Areas of anomalously high IVT values are located at the eastern and western edges of the ridge, indicating that moisture is transported eastward around the ridge (Fig. 5f). Note, however, that anomalously high westerly to southwesterly IVT is also present between lon* $=+60^{\circ}$ and lon* $=+80^{\circ}$ extending from $30^{\circ} \mathrm{N}$ and well into the PEA domain (Fig. 5f). While no downstream trough is apparent in the composite, this feature nevertheless indicates that moisture transport into the PEA domain occurs in numerous cases. The significant PV anomalies in the strong ridge persist until $+60 \mathrm{~h}$ and a new negative PV anomaly forms downstream of the PEA domain from $+48 \mathrm{~h}$ onward (Fig. $5 \mathrm{~g}, t_{\mathrm{int}}+72 \mathrm{~h}$ ). The significant high IVT in the PEA 

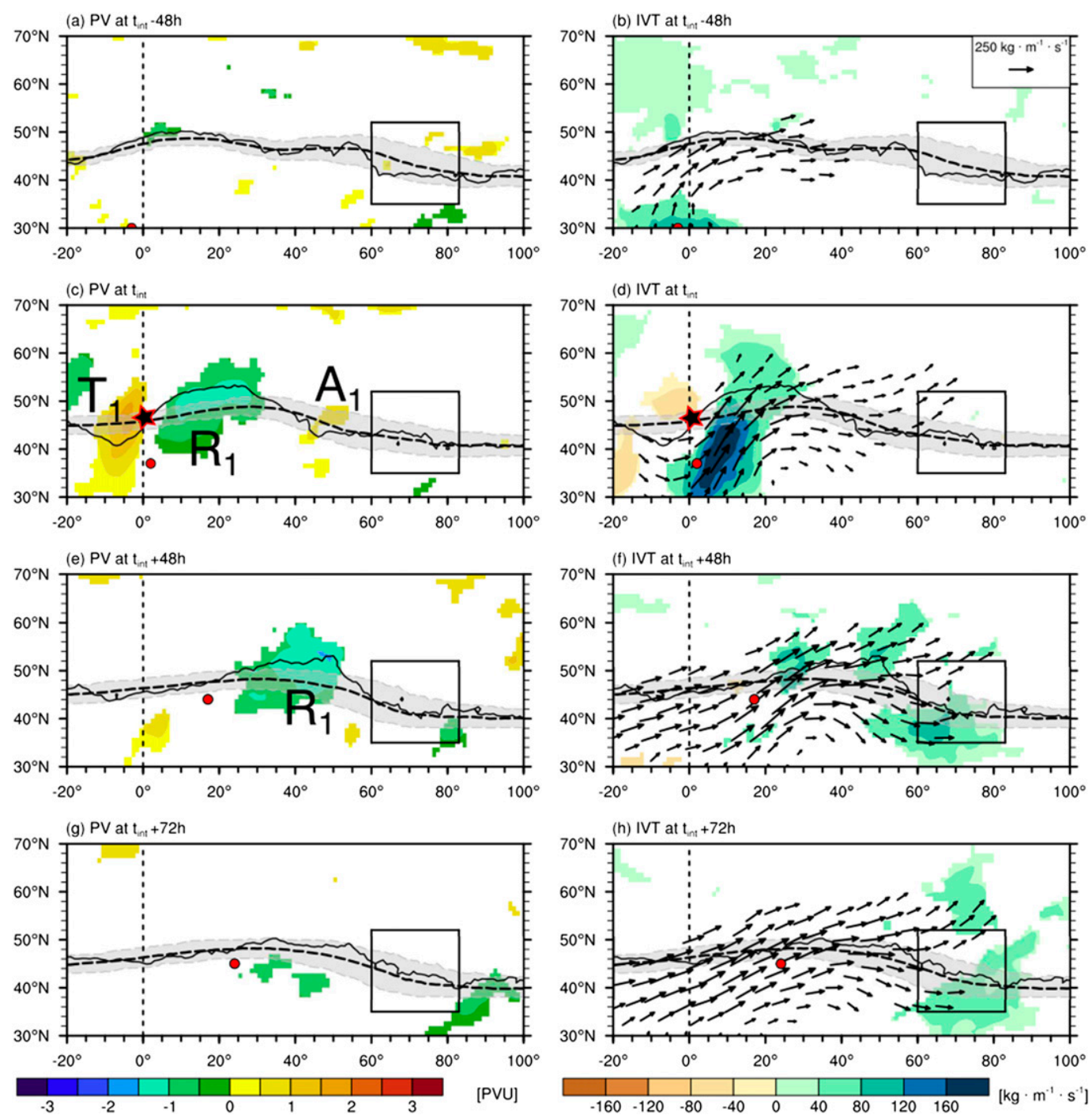

FIG. 5. Anomalies of (a),(c),(e),(g) PV and (b),(d),(f),(h) IVT composite fields (color shading) at lags (a), (b) $-48 \mathrm{~h},(\mathrm{c}),(\mathrm{d}) 0 \mathrm{~h},(\mathrm{e}),(\mathrm{f})+48 \mathrm{~h}$, and $(\mathrm{g}),(\mathrm{h})+72 \mathrm{~h}$. The isentropic level of each PV field used for the composites is selected as detailed in section 2a. Vectors in (b),(d),(f),(h) indicate the direction and magnitude of IVT. The solid black contour indicates where 50\% of the fields used for the PV composite exhibit PV values of 2 PVU or more to the poleward side of the contour (limit between tropospheric and stratospheric air) and is a proxy for the location the jet stream. Dashed black lines indicate the mean position of the same dynamic tropopause proxy for the 1000 analog composites. Gray shadings around the dashed lines indicate the 5th-95th percentile confidence interval of this position. The red dot on each panel indicates the average location of the recurving tropical cyclones. The star in (c) and (d) indicates the location of the maximum interaction point. The black rectangle indicates the position of the PEA domain and the vertical dashed line corresponds to the longitude of maximum interaction.

domain appears at $+18 \mathrm{~h}$ and persists until $+72 \mathrm{~h}$ (Fig. $5 \mathrm{~h}$ ) with a maximum spatial extent at $+54 \mathrm{~h}$.

In summary, we find a statistically significant increase in the spatial extent of extreme precipitation in the PEA domain between 42 and $90 \mathrm{~h}$ after $t_{\text {int }}$ (i.e., on average over central Europe). Composite PV and IVT fields indicate a more amplified midlatitude flow in the presence of recurving TCs compared to the analogs and a significantly increased IVT into the PEA domain.

\section{b. Recurrent midlatitude flow patterns modulating the downstream response of recurving TCs}

\section{1) UPPER-LEVEL FLOW CONFIGURATIONS/ CHARACTERISTICS}

Previous studies suggested that the response of the extratropical flow to recurving tropical cyclones is sensitive to its configuration during the interaction; in particular the strength of the extratropical jet, the presence or absence of 

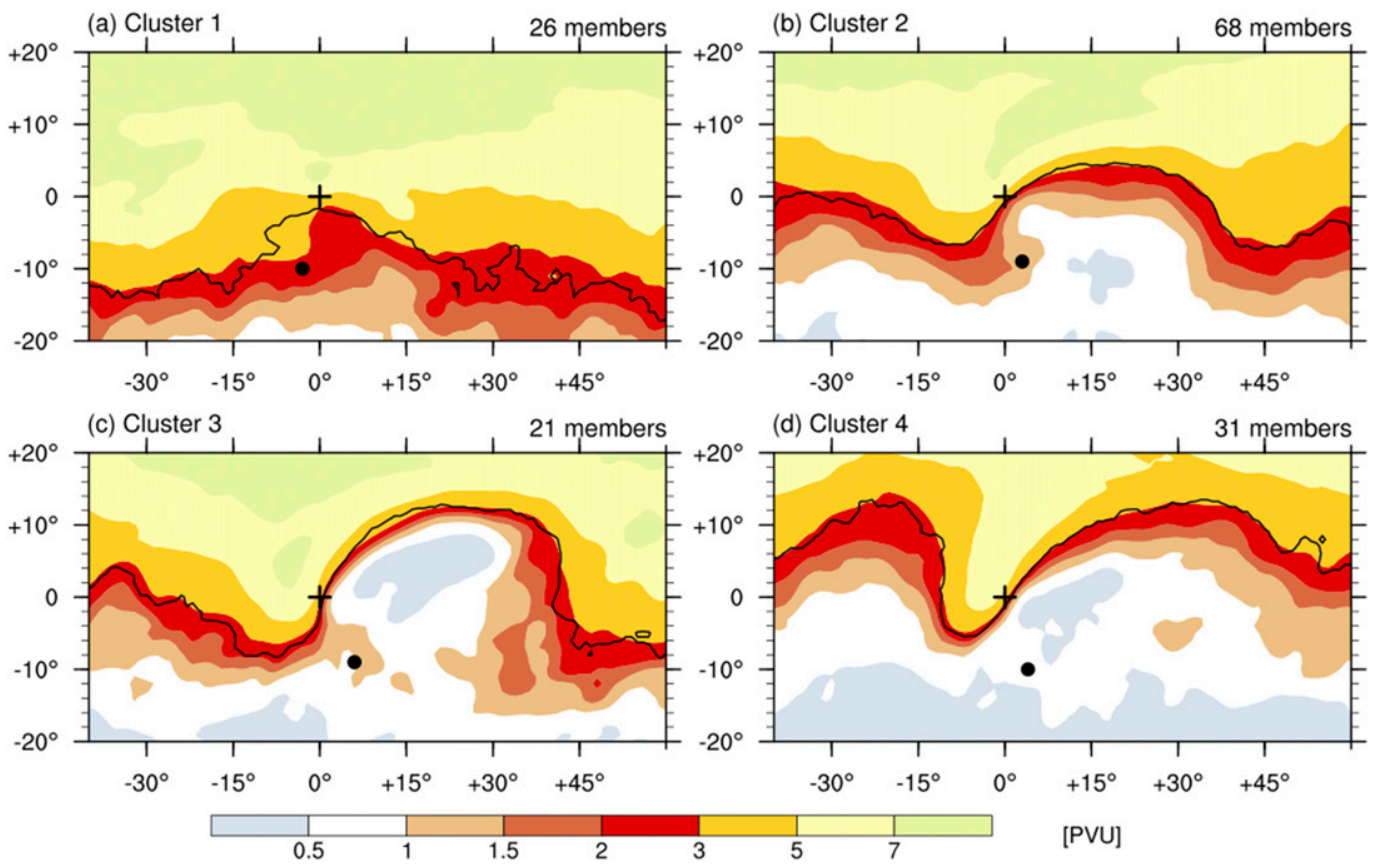

(d) Cluster 4

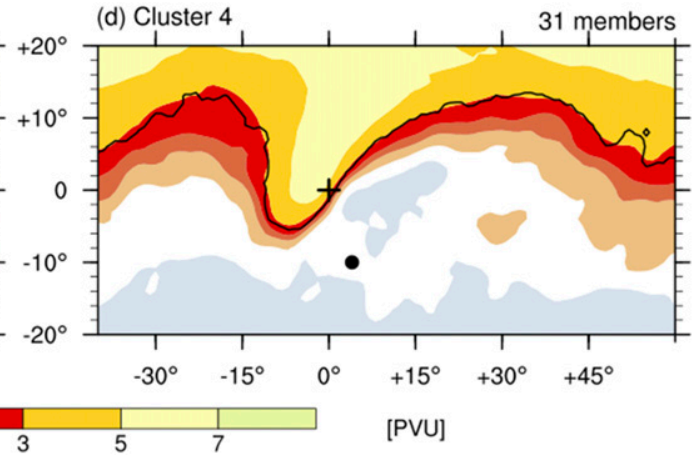

FIG. 6. (a)-(d) Composite PV fields at $t_{\text {int }}$ (color shading, PVU) for each of the four clusters. As previously, the isentropic level of each PV field constituting the composites is based on the date of the year (cf. section 2a). The solid black contour indicates where $50 \%$ of the fields used for the PV composite exhibit PV values of 2 PVU or more to the poleward side of the contour (limit between tropospheric and stratospheric air) and is a proxy for the location the jet stream. The black cross and dot, respectively, mark the location of the maximum interaction point and the mean location of the recurving TC.

an upstream trough, or a preamplified upper-level waveguide are key factors in modulating the downstream response of TC-jet interactions (Pinto et al. 2001; Ritchie and Elsberry 2001, 2003, 2007; Riemer et al. 2008; Riemer and Jones 2010, 2014, Archambault et al. 2013, 2015; Grams et al. 2013; Pantillon et al. 2015; Torn and Hakim 2015; Riboldi et al. 2018). Therefore, as a next step in this analysis, we aim to determine which flow configurations are more likely to be followed by an increased PEA after a TC-jet interaction.

To do so, we cluster the 146 recurving TC cases into four clusters based on their $\ln (\mathrm{PV})$ field at $t_{\text {int }}$ in the clustering domain using a $K$-means cluster analysis (Wilks 2006) (cf. section 2e). The resulting clusters are shown in Fig. 6. In addition, the intracluster variability is shown in Fig. S2 in the supplemental material. The first cluster has 26 members, corresponding to $18 \%$ of all recurvature cases. It is characterized by PV gradients, generally weaker compared to the other clusters, in the vicinity of the interaction point at $t_{\text {int }}$ and a zonally oriented dynamical tropopause (and jet) in $\pm 15^{\circ}$ of longitude around the interaction point (Fig. 6a). This cluster has the largest intracluster variability in terms of $D$ and midlatitude waveguide location (Fig. S2a in the supplemental material) and the weak gradients are partly due to a large case-to-case variability. Moreover, there is no coherent signal of a trough being present upstream of the interaction point. The interaction points of the cases falling into this cluster tend to be located at high latitudes (Fig. 2).

The second cluster contains 68 cases, corresponding to $46 \%$ of all cases. This cluster is characterized by strong PV gradients in the vicinity of the interaction point (Fig. 6b). A negatively tilted trough is present upstream of the interaction point extending approximately $5^{\circ}$ to the south of the interaction point. Moreover, a ridge extends downstream, from lon $*=0^{\circ}$ to approximately lon* $=+35^{\circ}$ east of the interaction point. The northern edge of the ridge is located approximately $5^{\circ}$ north of the interaction point. All the points of maximum interaction from cluster 2 are located roughly between $45^{\circ}$ and $55^{\circ} \mathrm{N}$ (Fig. 2).

The third cluster contains 21 cases, corresponding to $14 \%$ of all cases. This cluster is characterized by a strong PV gradient and jet stream in the vicinity of the interaction point (Fig. 6c). A negatively tilted trough is present upstream of the interaction point and extends approximately $10^{\circ}$ to the south. An amplified ridge is located downstream of the interaction point extending from lon $*=0^{\circ}$ to approximately lon* $=+40^{\circ}$. The northern 
edge of the ridge is located around $15^{\circ}$ north of the interaction point. Hence, the flow is even more meridionally amplified in cluster 3 than in cluster 2 . The dynamic tropopause is indeed oriented almost meridionally at the interaction point. The points of maximum interaction of this cluster are located south of $45^{\circ} \mathrm{N}$ (Fig. 2).

The fourth cluster contains 31 cases, corresponding to approximately $21 \%$ of the total number. It is characterized by the strongest PV gradients in the vicinity of the interaction point among all the four clusters. A positively tilted trough is located upstream of the point of interaction and extends roughly $5^{\circ}$ to the south. A broad downstream ridge extends from lon* $=0^{\circ}$ to lon $*=+50^{\circ}$ downstream of the interaction point. The northern edge of the ridge is located $10^{\circ}$ north of the interaction point. While the meridional amplification of the wave patterns is similar to cluster 3 , the downstream ridge is much broader, and the upstream trough is positively tilted and is much narrower. The upstream trough is preceded by an upstream ridge. This ridge is notably different from clusters 1,2 , and 3 and is conceivably of importance in the downstream flow development leading to a PEA increase. Furthermore, the interaction points are located on average at the lowest latitudes and reach as far south as $35^{\circ} \mathrm{N}$ (Fig. 2). In summary, the clustering revealed substantial differences in the largescale flow configuration in which recurving TCs occur, with the upstream trough and downstream ridge being more pronounced the farther south TC-midlatitude flow interaction occurs. Finally, a seasonal analysis revealed that no distinct seasonality was observed between each cluster.

\section{2) Evolution of PEA FOR THE DIFFERENT CLUSTERS}

Along with the different large-scale flow patterns, the clusters also exhibit substantial differences in the evolution of the PEA. For cluster 1, there is no significant increase in the PEA after the TC-jet interaction (Fig. 7a). In cluster 2 the PEA significantly increases between lags +42 and $+78 \mathrm{~h}$ and peaks at $+72 \mathrm{~h}$ after $t_{\text {int }}$ (Fig. 7c). PEA for the third cluster significantly exceeds the variability of the PEA distribution from the analogs sample at lags +12 to $+18 \mathrm{~h}$. At lag $+72 \mathrm{~h}$, the PEA peaks at $2.5 \%$ (Fig. 7e). However, interestingly, this peak remains within the confidence interval of the analog mean PEA distribution, as in this cluster, the PEA of analogs increases too (99th percentile peaks at $2.8 \%$ ). This finding indicates that the cluster 3 flow configuration is favorable to extreme precipitation events irrespective of a TC-jet interaction.

For cluster 4, we find a significant increase in mean PEA between 36 and $90 \mathrm{~h}$ after $t_{\text {int }}$ (Fig. $7 \mathrm{~g}$ ). This increase is substantial, as the mean PEA values exceed the mean analog PEA by a factor of 3 . Hereby the timing of the mean PEA peak is similar to the timing of the PEA peaks for the other clusters. This flow setting is hence the most conducive for TC-jet interactions to influence downstream precipitation extremes. As in section 3a, Figs. 7b, $\mathrm{d}, \mathrm{f}, \mathrm{h}$ provide additional information about the intracluster spread in the PEA time series, indicating a magnitude and time variability between each case.

\section{3) EVOLUTION OF THE UPPER-LEVEL FLOW AND MOISTURE TRANSPORT FOR EACH CLUSTER}

The differences in the downstream precipitation extremes for the four clusters are conceivably related to a different upper-level flow evolution and moisture transport. Therefore, we analyze in detail the significant deviations of the composite PV and IVT fields from the analog composites for each cluster.

PV and IVT composites for cluster 1 are characterized by the absence of significant and coherent signals, both at $t_{\text {int }}$ and during the following days (Fig. 8). This is in agreement with the lack of a significant increase in PEA for this cluster and with the large variability among the individual cases contributing to this cluster.

For cluster 2 no significant deviations of the upperlevel PV from the analog cases are present $48 \mathrm{~h}$ prior to

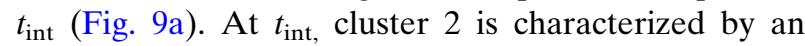
anomalous trough $\left(\mathrm{T}_{1}\right)$ upstream of the point of maximum interaction, a ridge $\left(\mathrm{R}_{1}\right)$ extending downstream from lon $*=+5^{\circ}$ to lon* $=+30^{\circ}$ and a second trough $\left(\mathrm{T}_{2}\right)$ located $40^{\circ}$ to the east (Fig. 9c). This second PV trough $\left(\mathrm{T}_{2}\right)$ decays after $+24 \mathrm{~h}$ (not shown). At $t_{\text {int }}+48 \mathrm{~h}$ the anomalous $\mathrm{R}_{1}$ ridge is centered at lon* $=+40^{\circ}$ (Fig. 9e) but vanishes after $+54 \mathrm{~h}$ (not shown). IVT at $t_{\text {int }}$ is significantly increased just downstream of the point of maximum interaction (Fig. 9d) and two days later IVT is significantly increased around the ridge $\left(\mathrm{R}_{1}\right)$ and in the southern part of the PEA domain (Fig. 9f), which coincides with the timing of significant PEA increase (Fig. 7c). At $t_{\text {int }}+72 \mathrm{~h}$, the PV field appears again more similar to the analogs (Fig. 9g). A positive IVT anomaly persists in the southernmost part of the PEA domain with a rather westerly flow (Fig. 9h).

In cluster 3, no significant PV structures are present in the vicinity of the maximum interaction point two days prior to $t_{\text {int }}$ (Fig. 10a) and the significantly increased IVT is confined to areas around the average TCs location (Fig. 10b). At $t_{\text {int }}$, an anomalous trough $\left(\mathrm{T}_{1}\right)$ is present immediately upstream of the maximum interaction point and a ridge $\left(\mathrm{R}_{1}\right)$ extends downstream, between $0^{\circ}$ and $+35^{\circ}$ (Fig. 10c). The ridge $\left(\mathrm{R}_{1}\right)$ is followed by a pronounced trough $\left(\mathrm{T}_{2}\right)$ centered at lon* $=+50^{\circ}$ (Fig. 10c). At the same time, significantly increased IVT 
(a)

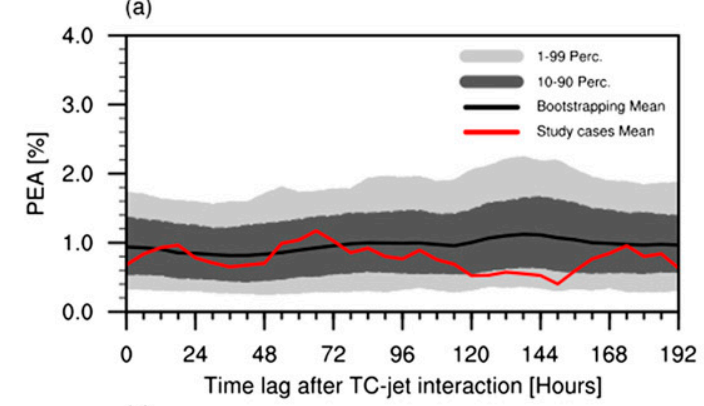

(c)

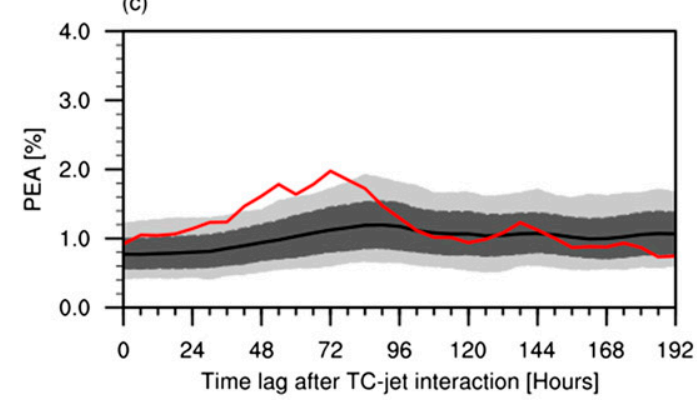

(e)

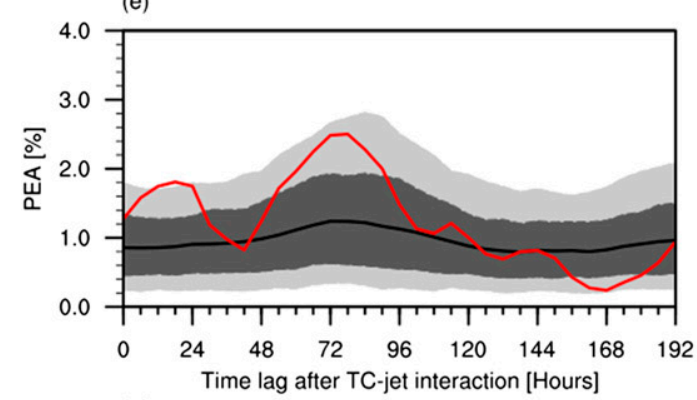

(g)

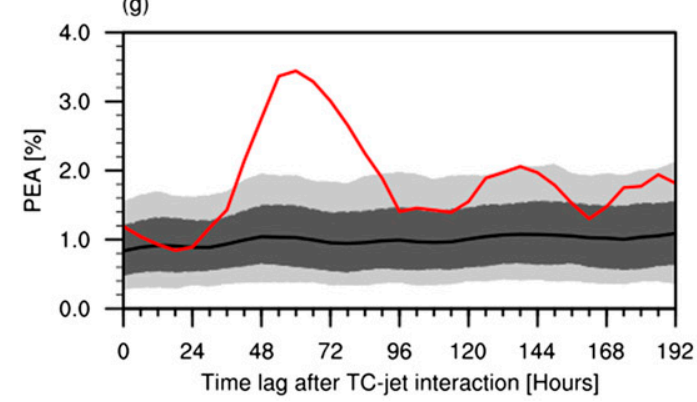

(b)

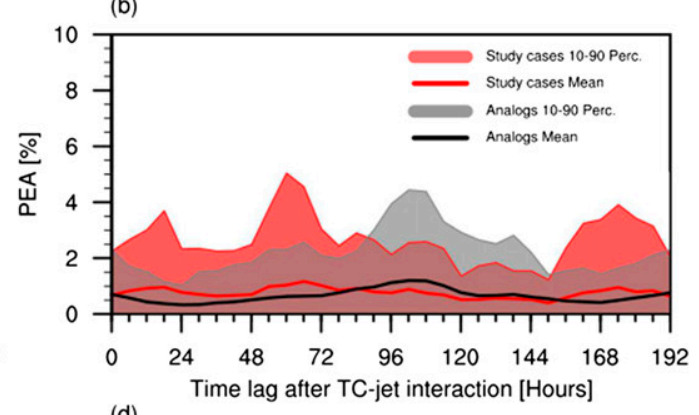

(d)

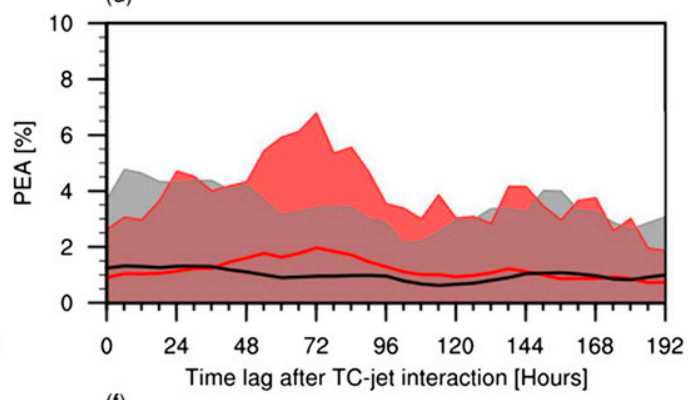

(f)

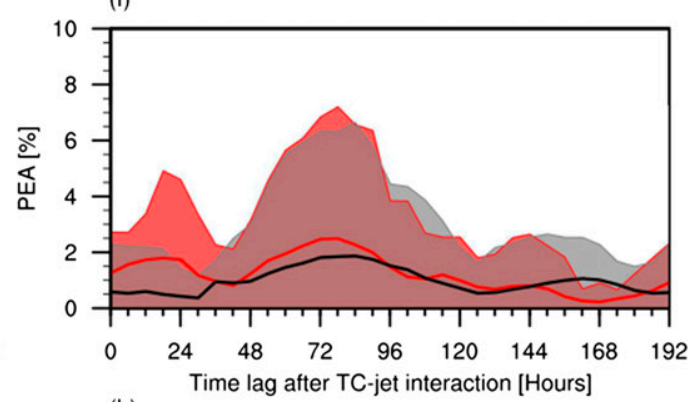

(h)

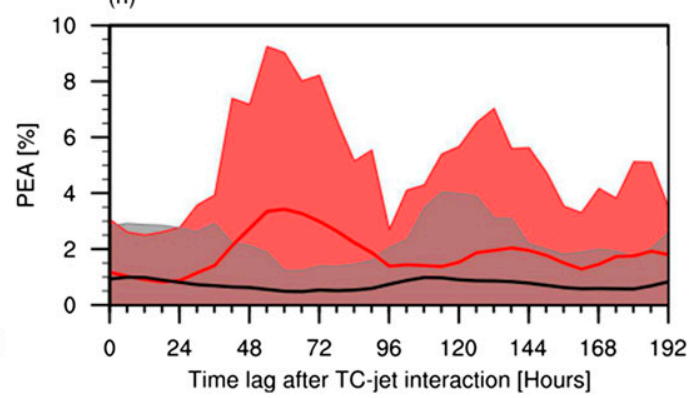

FIG. 7. As in Fig. 4, but for each cluster: (a),(b) cluster 1, (c),(d) cluster 2, (e),(f) cluster 3, and (g),(h) cluster 4.

values are present in the western half of ridge $\left(\mathrm{R}_{1}\right)$ between $0^{\circ}$ and $+20^{\circ}$ extending from $30^{\circ}$ to $60^{\circ} \mathrm{N}$ (Fig. 10d). A second, smaller statistically significant high IVT area is located downstream of the trough $\left(\mathrm{T}_{2}\right)$ between $+65^{\circ}$ and $+70^{\circ}$. This feature co-occurs with the first extreme precipitation peak observed $12 \mathrm{~h}$ after $t_{\text {int }}$ (Fig. 7e). Moreover, the approaching upper-level trough can be expected to provide quasigeostrophic lifting and also fosters moisture transport into the PEA domain. The cooccurrence of the two features thus seems to be a plausible explanation for the observed increase in precipitation extremes in the PEA box. Indeed, at $+12 \mathrm{~h}$, trough $\left(\mathrm{T}_{2}\right)$ is located directly upstream of the PEA domain and is extending significantly further south than the analog patterns (see Fig. S4), although IVT values are no longer significantly higher in the PEA domain at this time. At $+48 \mathrm{~h}$, significantly increased IVT is present in the PEA domain (Fig. 10f) and the flow is highly amplified (Figs. 10e,f). However, the trough over the PEA domain is not significantly deeper or more amplified meridionally than the most amplified analog composites. A positive PV anomaly can be observed at the southernmost edge 

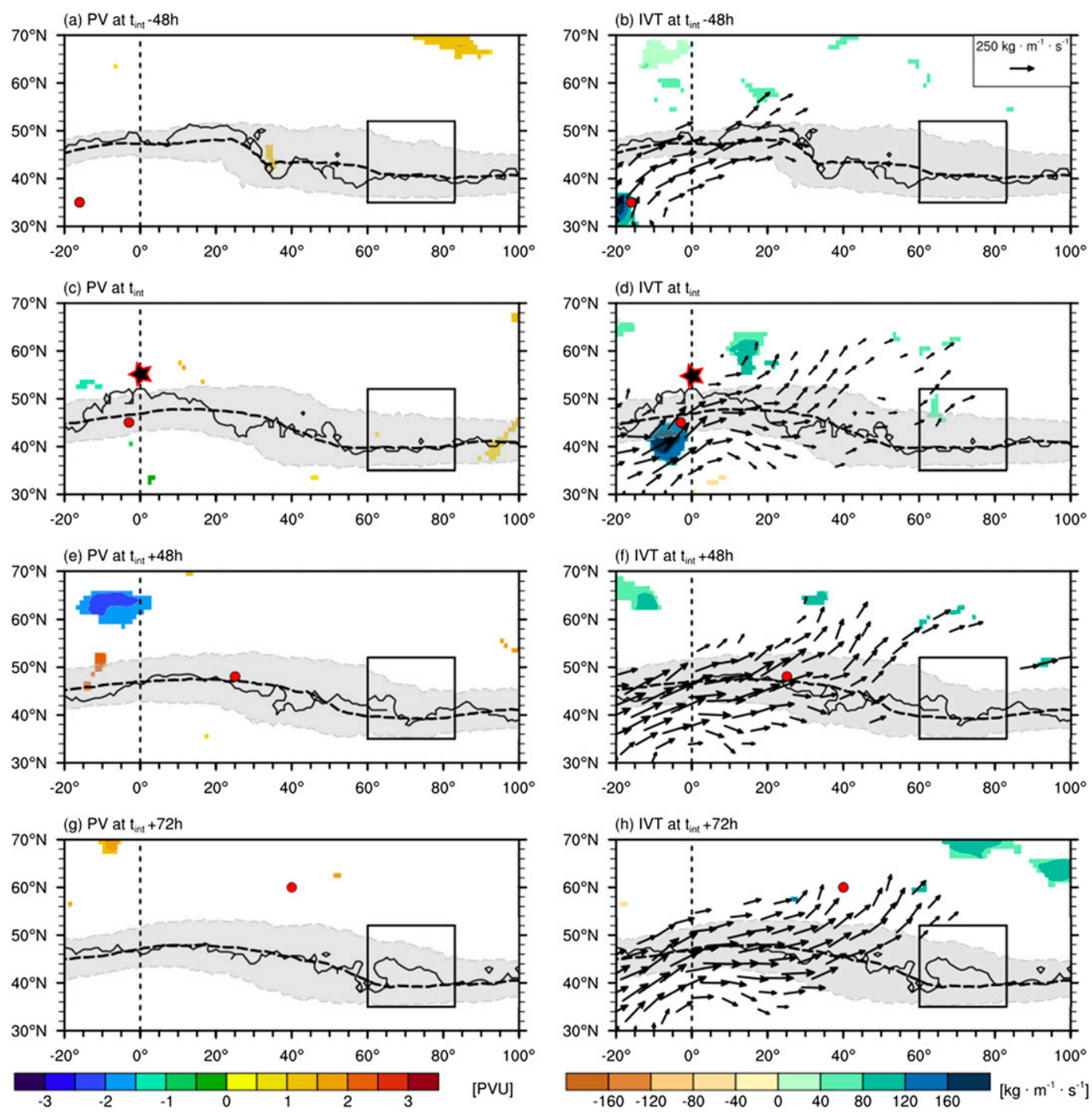

FIG. 8. As in Fig. 5, but for cluster 1.

of $\mathrm{T}_{2}$ (Fig. 10e), indicating that meridionally amplified cases of cluster 3 are prone for the formation of downstream PV cutoffs. 24h later, the composite upper-level flow attenuates slightly (Fig. 10g), but southerly positive IVT anomalies can still be observed within the PEA domain (Fig. 10h). At this time the PEA is increased compared to climatology both in the analog sample as well as in the TC-jet interaction composite, but there are no significant differences between the two. This observation, together with the results presented in Fig. $7 \mathrm{e}$ indicates that cluster 3 cases occur in an extratropical flow setting that is preamplified and already conducive to an increase in PEA. Therefore, the PEA increase for this cluster cannot be attributed solely to the TC-jet interaction (Fig. 7e).

Finally, in cluster 4, small areas of positive PV anomalies in a trough upstream of the point of maximum interaction $\left(\mathrm{T}_{1}\right)$ are visible two days prior to $t_{\mathrm{int}}$
(Fig. 11a). The composite PV anomalies at $t_{\text {int }}$ indicate that trough $\left(\mathrm{T}_{1}\right)$ has developed into an amplified, positively tilted trough, upstream of the point of maximum interaction. At $t_{\text {int }}$, a broad downstream ridge $\left(\mathrm{R}_{1}\right)$ is centered at lon $*=+30^{\circ}$ (Fig. 11c). The trough-ridge $\left(\mathrm{T}_{1}-\mathrm{R}_{1}\right)$ couplet is associated with anomalously high IVT values downstream of the trough, extending from $30^{\circ}$ to $50^{\circ} \mathrm{N}$ (Fig. $11 \mathrm{~d}$ ). At $+48 \mathrm{~h}$, ridge $\left(\mathrm{R}_{1}\right)$ extends all the way to lon* $=+70^{\circ}$ and a weak but not significantly amplified trough $\left(\mathrm{T}_{2}\right)$ is located downstream of the ridge $\left(\mathrm{R}_{1}\right)$ in the PEA domain (Figs. 11e,f). Anomalously high IVT values are present within the ridge, in particular along its northern flanks. The high IVT values extend into the PEA domain (Fig. 11f), supplying moisture for extreme precipitation between $t_{\text {int }}+42 \mathrm{~h}$ and $t_{\text {int }}+84 \mathrm{~h}$ (Fig. $7 \mathrm{~g}$ ). The significantly increased IVT in the PEA domain persists from +30 to $+72 \mathrm{~h}$ (Fig. 11h) with 

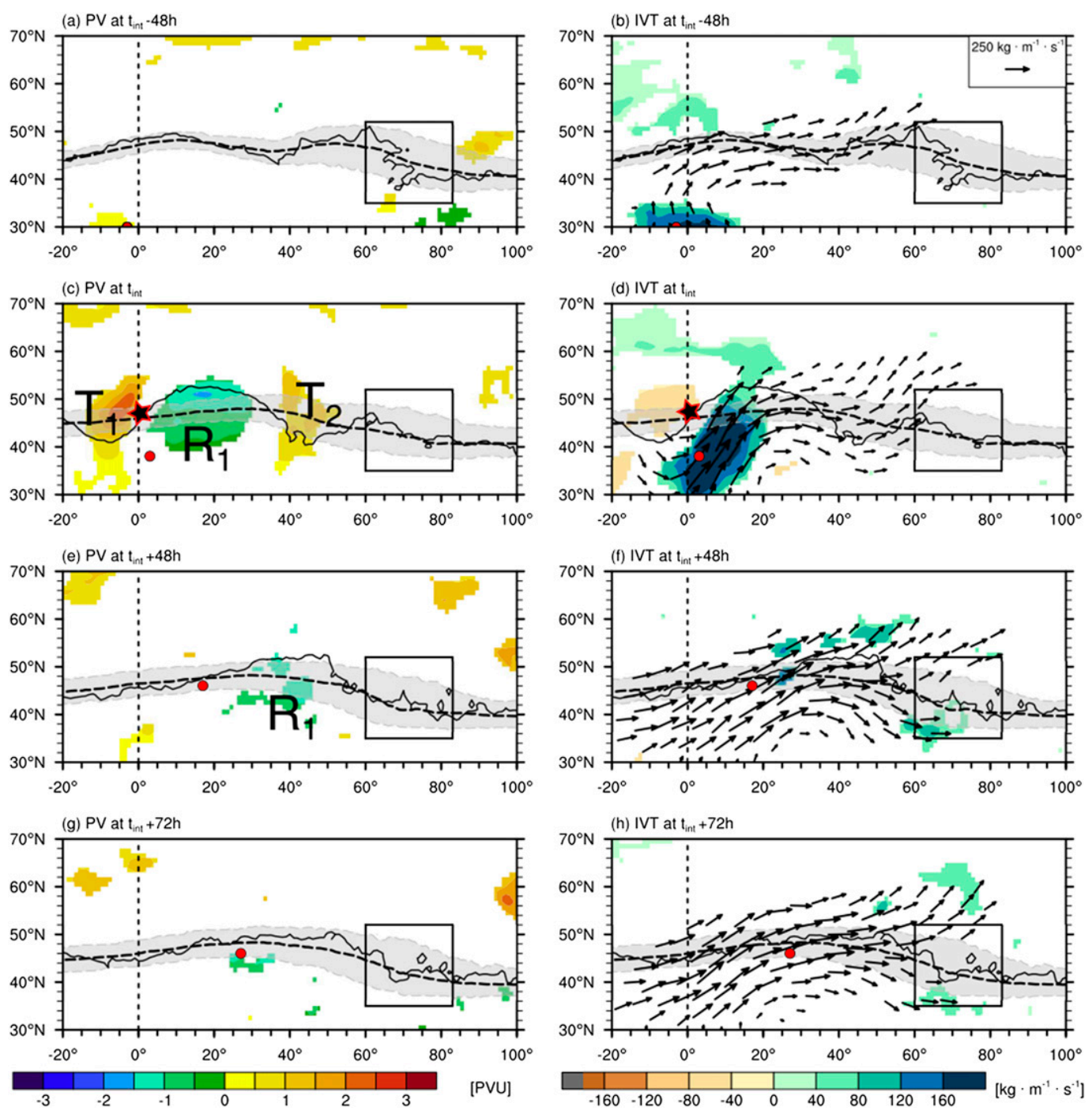

FIG. 9. As in Fig. 5, but for cluster 2.

maximum spatial extension at $+54 \mathrm{~h}$ (not shown), therefore matching the observed increase in the PEA. This indicates that, for cases belonging to cluster 4 , the presence of a TC-jet interaction in the North Atlantic is pivotal for increasing the PEA over Europe.

\section{Discussion and summary}

Our results illustrate the statistically significant role of TC-jet interactions and associated enhanced moisture transport into the PEA domain for the formation of downstream precipitation extremes. The observed increase in PEA, $60^{\circ}-83^{\circ}$ of longitude downstream of the point of interaction, $48-72 \mathrm{~h}$ after $t_{\text {int }}$ is consistent with a typical group velocity of synoptic-scale Rossby wave packets (roughly $20^{\circ}-30^{\circ}$ longitude day ${ }^{-1}$ ) in the North Atlantic (Chang and Yu 1999; Torn and Hakim 2015;
Wirth et al. 2018). However, not every recurving TC in the Atlantic is linked to downstream precipitation extremes and the presented results are subject to case-tocase variability.

Our analysis highlights the dependence of the timing and spatial extent of downstream precipitation extremes on the large-scale extratropical flow over the North Atlantic during TC-midlatitude flow interaction. The upper-level flow and moisture transport of the four clusters are schematically summarized in Fig. 12. The first cluster is characterized by an almost zonal cluster mean flow with weak meridional PV gradients (Figs. 6a and $12 \mathrm{a}, \mathrm{b}$ ) and a large intracluster variability. There is no significant downstream amplification of the flow pattern or high IVT toward the PEA domain in the days following $t_{\text {int }}$ (Fig. 12b), and consequently, no increase in downstream precipitation extremes (Fig. 7a). 

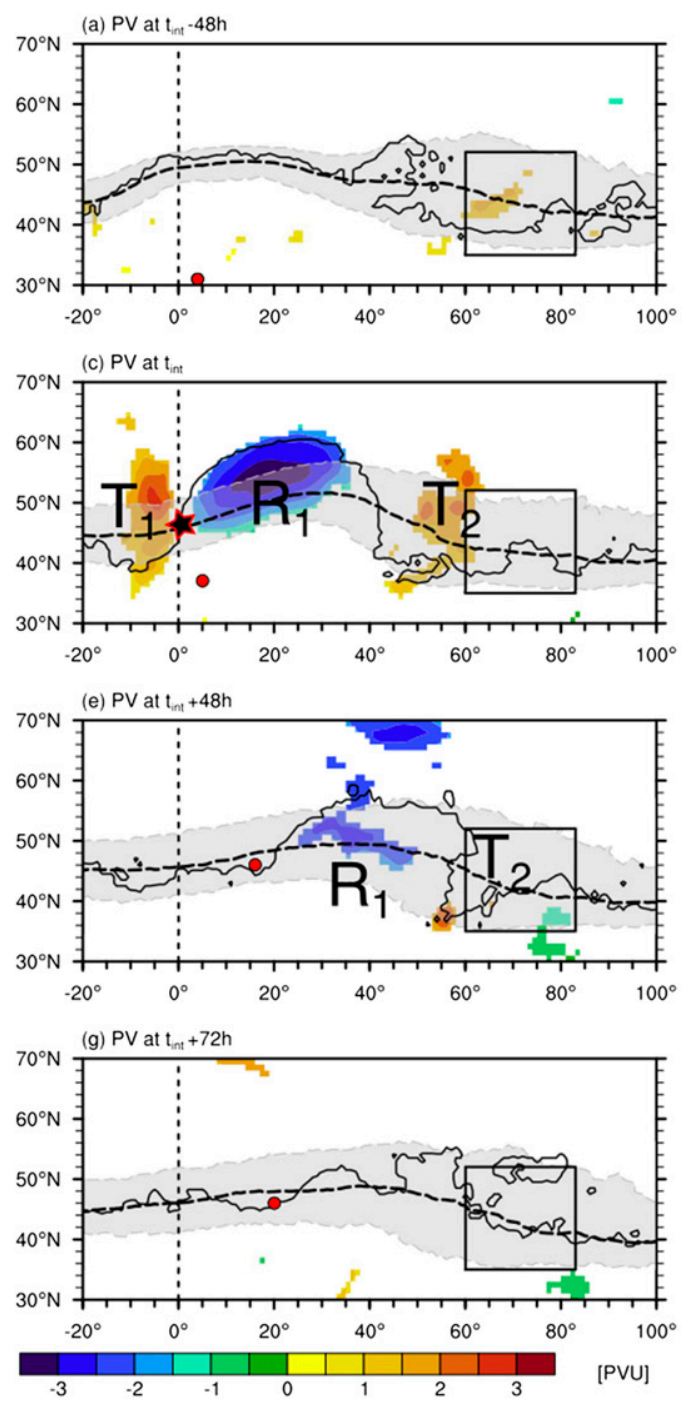
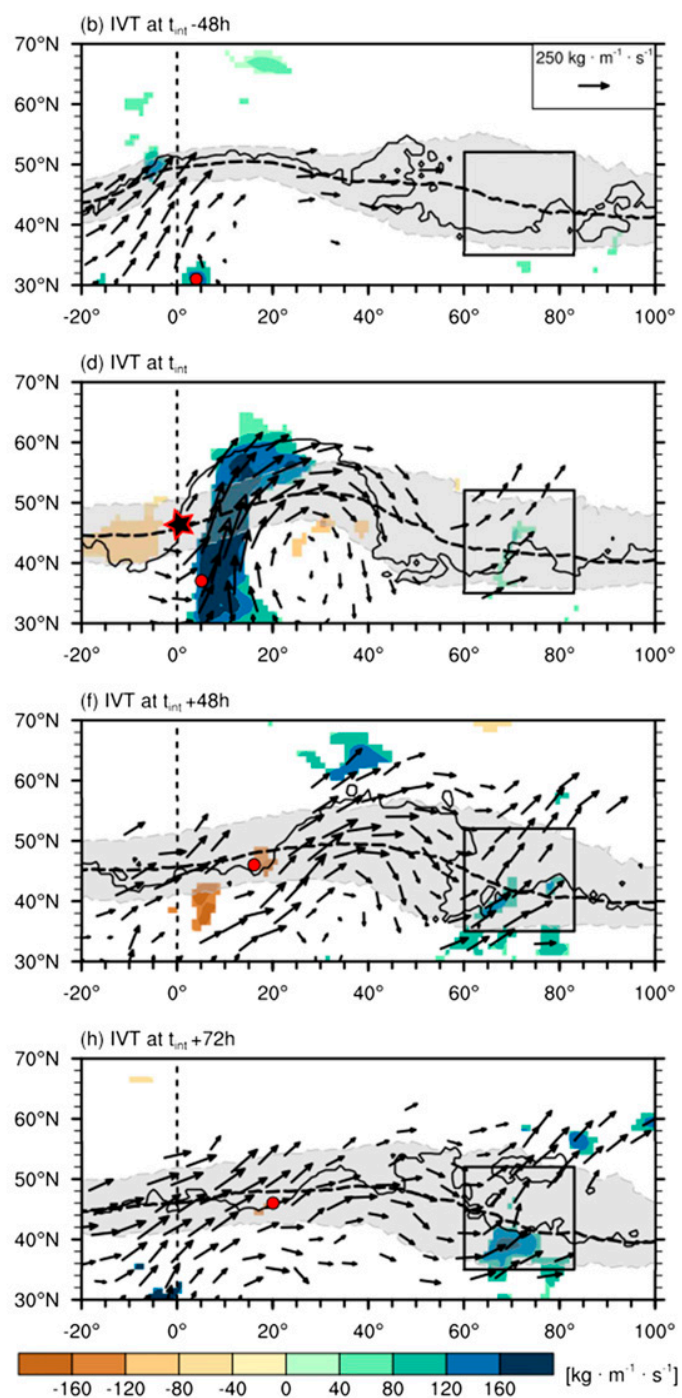

FIG. 10. As in Fig. 5, but for cluster 3.

The second cluster exhibits a significant increase of downstream precipitation extremes $1.5-3$ days after $t_{\text {int }}$ (Fig. 7c). The extratropical flow at $t_{\text {int }}$ is characterized by an upstream trough and a downstream ridge surrounding the interaction point and by significantly increased moisture transport into this ridge by the TC (Fig. 12c). Two days later, anomalously high IVT reaches the PEA domain from the west (Fig. 12d).

Cluster 3 is associated with a weak but significant increase in precipitation extremes $12 \mathrm{~h}$ after $t_{\text {int }}$ and a strong but nonsignificant increase in precipitation extremes approximately 2 days later. The extratropical flow at $t_{\text {int }}$ is characterized by a meridionally amplified trough-ridge couplet centered on the TC-jet interaction point and increased poleward moisture transport into the ridge (Fig. 12e). Two days later, the cluster mean flow contains a meridionally elongated trough located approximately $60^{\circ}$ downstream of the maximum interaction point (Fig. 12f). Concomitantly, significantly increased moisture fluxes ahead of the downstream trough potentially contribute to the (nonsignificant) increase in precipitation extremes over the area.

Cluster 4 is associated with a significant and substantial ( 3 times the corresponding value from the ana$\operatorname{logs})$ increase of PEA between 1.5 and 3.5 days after $t_{\text {int }}$ (Fig. $7 \mathrm{~g}$ ). At $t_{\text {int }}$, the flow is characterized by a meridionally amplified trough-ridge pattern centered on the maximum interaction point and a high northward moisture flux into the ridge. In contrast to cluster 3 , the upstream trough is meridionally more elongated and positively tilted, hinting to the typical structure of anticyclonic wavebreaking upstream of the trough. Two days later, a broad trough is located approximately $60^{\circ}$ downstream of the maximum interaction point. 

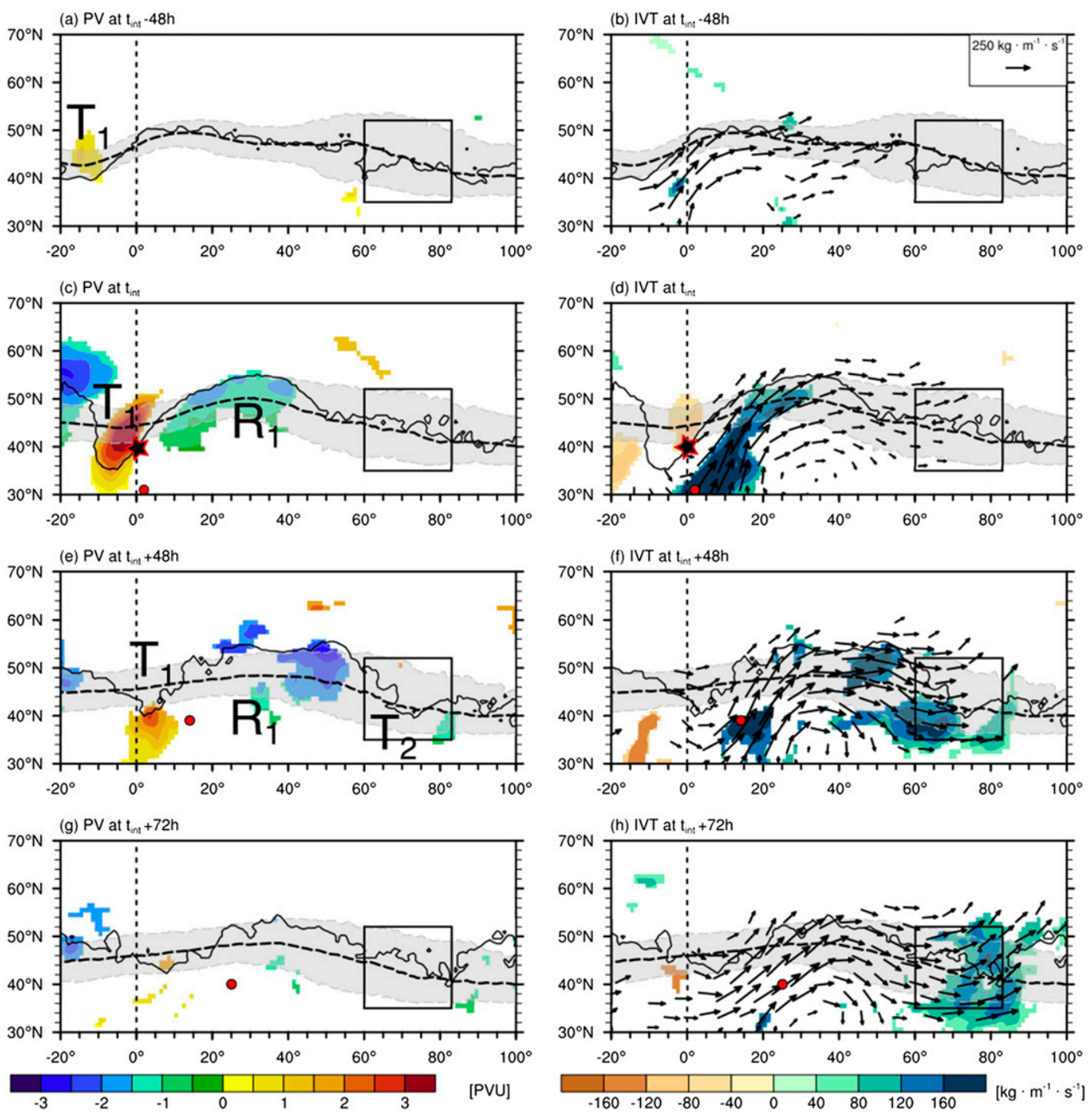

FIG. 11. As in Fig. 5, but for cluster 4. At $t_{\text {int }}-48 \mathrm{~h}$ in (a) and (b), the mean location of the recurving TCs is $24^{\circ} \mathrm{N}$ and lon $*=0^{\circ}$.

The time evolution of the anomalously high IVT suggests that high moisture flux mainly reaches the target area (PEA domain) along the downstream ridge. However, Figs. 11f,h show southwesterly flow into the PEA domain, indicating moisture transport along a downstream trough in some cases.

Building on our climatological investigation and the early work of Pinto et al. (2001), we therefore propose two main pathways that support the development of extreme precipitation events over Europe following the recurvature of North Atlantic TCs:

1) the "atmospheric river-like" mechanism, with anomalously high IVT that moves northward ahead of the recurving $\mathrm{TC}$ and into the downstream ridge, and
2) the "downstream-development" mechanism, with anomalously high IVT ahead of the downstream trough.

The atmospheric river-like mechanism is characterized by enhanced moisture flux along the flanks of a downstream ridge and the formation of high IVT areas that steers humid air into Europe [cf. case B events of Pinto et al. (2001)]. This flow configuration resembles the TC-noRWI cases (cases of TC-jet interaction, with no Rossby waves initiation) of Riboldi et al. (2018), and the formation of atmospheric rivers following the recurvature of TCs in the western North Pacific described by Cordeira et al. (2013). Cases following the atmospheric river-like mechanism are contained in clusters 2 and 4 (Figs. 12c,d and 12g,h). It is important to note that the 

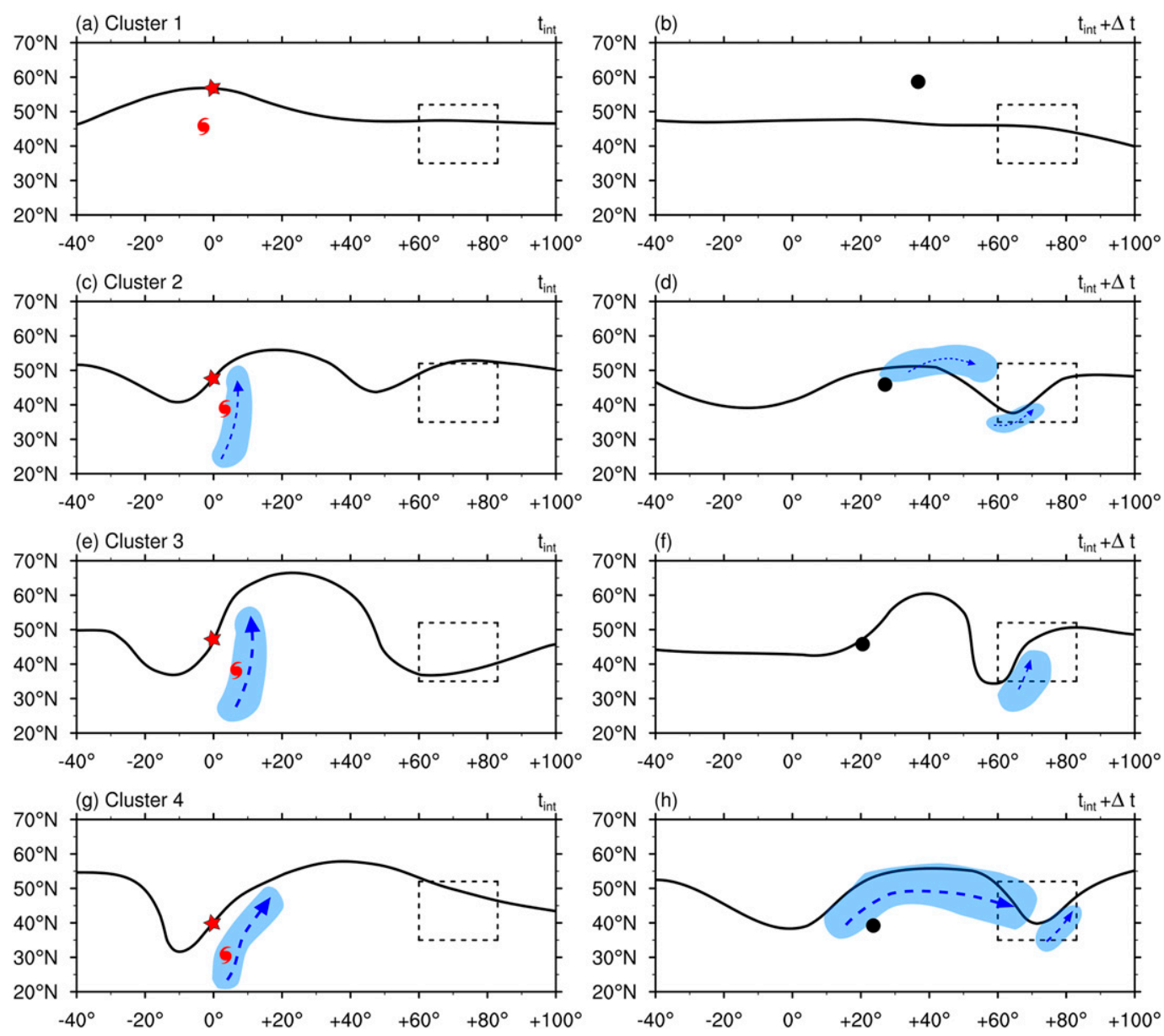

FIG. 12. Schematic of TC-jet interactions for each cluster. (a),(c),(e),(g) The flow pattern around the interaction point at $t_{\text {int }}$. The black line represents the isentropic 2-PVU contour collocated with the extratropical jet stream (cf. section 2a for isentropic level selection). The average position of the recurving TCs and interaction points are indicated by the TC symbol and red star, respectively. Blue shadings indicate regions of anomalously high integrated vapor transport and the blue arrows indicate the main direction of the water transport. (b),(d),(f),(h) The main direction of the water vapor transport at a time lag corresponding to the increase in precipitation extremes in the PEA domain. The black dots indicate the average location of the TC's remnant. The dashed squares indicate the location of the PEA domain. The different patterns are indicative of the main pathways that are conducive to the development of extreme precipitation events following TC recurvature.

moisture related to the high precipitation event does not necessarily originate from the tropical plume of the TC, as atmospheric rivers are characterized by local moisture convergence, strong precipitation and evaporation along their path (Cordeira et al. 2013; Dacre et al. 2015). The Northern Alpine flood in October 2011 (Piaget et al. 2015) is a prominent example of the atmospheric riverlike mechanism. In this case, enhanced moisture transport occurred along the flanks of a pronounced North Atlantic ridge and into Europe following the extratropical transition of Hurricane Philippe (member of cluster 4).

Extreme precipitation events following the downstream development mechanism are associated with high IVT ahead of an anomalously equatorward extended trough downstream of the TC-jet interaction point and are represented by cases in cluster 3 (Figs. 12e,f) [cf. case C of Pinto et al. (2001)]. This flow configuration is reminiscent of a classic flow configuration related to extreme precipitation events over the western Mediterranean (e.g., Toreti et al. 2016). The strong meridional amplification of the downstream trough is indicative of Rossby wave breaking and the formation of a PV streamer. Indeed, given that wave breaking/PV streamer formation occurs frequently over Europe and that extreme precipitation is regularly associated with these PV features (e.g., Martius et al. 2008; Nuissier et al. 2008; Romero et al. 1998; Giannakaki and Martius 2016; Toreti et al. 2016), there are many analogs of this pattern without transitioning TCs in the western Atlantic. 
Our significance testing correctly diagnoses an increase in the analog PEA for cluster 3 in the presence of a meridionally amplified flow pattern (Fig. 7c, from $0.9 \%$ to $1.1 \%$ for the mean and $1.7 \%$ to $2.8 \%$ for the 99 th percentile). Although the increase in PEA for the recurving TCs in cluster 3 is higher, this increase lies within the variability of the analog flow patterns and therefore we cannot attribute it primarily to the recurving TCs. However, previous case studies showed a causal link of TC midlatitude flow interaction and downstream extreme precipitation events for specific cases involving the downstream development mechanism (Grams and Blumer 2015; Pantillon et al. 2015; Barton et al. 2016).

These two mechanisms do not necessarily occur separately: jet streak formation downstream of a TC-jet interaction can promote moisture transport along the flanks of the downstream ridge (Cordeira et al. 2013) along with the formation of a downstream trough (Piaget et al. 2015). A combination of the two mechanisms is evident in clusters 2 and 4 (Figs. 12c,d and 12g,h), which exhibit anomalously high IVT both in the ridge and also show significant signatures ahead of the downstream trough.

Conversely, neither flow amplification nor enhanced IVT occurs for cases in the first cluster. Looking at the composites, we see that the average location of the interaction points of cluster 1 is located at the northern tip of a ridge, without the clear signature of an upstream trough and thus the transitioning TC misses an environment favorable for extratropical reintensification. Furthermore, many of these cases are related to a highlatitude interaction points (blue points in Fig. 2).

The diagnostic presented in this study has been designed to account for atmospheric flow patterns and we did not stratify cases according to other TC or ET characteristics, such as interaction strength or TC intensity. However, a statistical analysis of TC's central sea level pressure (in $\mathrm{hPa}$ ) and interaction's strength (expressed in PVU day ${ }^{-1} ; 1 \mathrm{PVU}=10^{-6} \mathrm{~K} \mathrm{~kg}^{-1} \mathrm{~m}^{2} \mathrm{~s}^{-1}$ ) indicated no significant difference between each cluster.

\section{Conclusions and outlook}

Several case studies have highlighted a possible link between recurving TCs and the occurrence of extreme weather events farther downstream. In this study, we analyze a sample of 146 TCs recurving in the North Atlantic basin to assess their relationship with extreme precipitation events over Europe. The statistical significance of all results is determined using a novel analog bootstrapping approach that allows us to distinguish the evolution of the large-scale atmospheric circulation after a TC-jet interaction from the evolution without a recurving $\mathrm{TC}$.
In the days after recurving TC events we find a significant increase in the area affected by extreme precipitation approximately one synoptic-scale Rossby wavelength $\left(60^{\circ}-83^{\circ}\right)$ downstream of the location of the $\mathrm{TC}$-jet stream interaction (i.e., in a region roughly corresponding to central Europe). The increase in the area affected by precipitation extremes is significant between +42 and $+90 \mathrm{~h}$ after the interaction time and the sample mean doubles compared to the analogs.

Furthermore, a cluster analysis highlights the processes related to the development of extreme precipitation events over Europe following the recurvature of North Atlantic TCs and extends the work previously conducted by Pinto et al. (2001). The presence of recurving TCs upstream of Europe can induce extreme precipitation by promoting moisture transport ahead of the first downstream trough (downstream development case, cluster 3) and/or in the first downstream ridge (atmospheric riverlike case, clusters 2 and 4).

Our statistical test revealed that attribution of extreme events to the TCs is much clearer for atmospheric riverlike cases than for downstream development cases. However, every attribution study must consider the specificities of each case and sensitivity studies using techniques like TC removal (as in, e.g., Grams and Blumer 2015) are unavoidable to correctly assess the actual impact of a specific recurving TC on the downstream flow.

Our results could be exploited for improving short- to medium-range forecasts of precipitation extremes during TC recurvature periods when the downstream predictability is often reduced (Anwender et al. 2008, Aiyyer 2015, Grams et al. 2015, Quinting and Jones 2016). The flow clusters could guide the evaluation of ensemble forecasts (e.g., by identifying flow analogs to the clusters linked to the highest fraction of downstream precipitation extremes in the medium-range forecasts).

Similar analyses could be carried out for other ocean basins. In particular, the impact of recurving TCs in the western and eastern Pacific basin on the occurrence of extremes downstream over North America and Europe would be of interest. In addition, a more detailed analysis of the source areas of the moisture rained out within the precipitation extremes is needed to further clarify the exact role of the TC for the formation of the precipitation extremes (see also section 4). In addition, a climate projection study by Liu et al. (2017) suggests that the number of extratropical transitions is most likely going to increase in the eastern North Atlantic during the twenty-first century in a warmer climate. This, in combination with an increasing moisture content of a warmer atmosphere, would point toward an increasing relevance of TC recurvature for downstream precipitation extremes and warrants further investigation. 
Acknowledgments. Parts of this research have been published in the M.Sc. thesis of Roman Pohorsky. This research was supported by the Swiss National Science Foundation (SNSF), Grant 200021_159905. The contribution of CMG was supported by the SNSF, Grant PZ00P2_148177/1 and completed while he holds a Young Investigator Group grant by the German Helmholtz Association (VH-NG-1243). The contribution of JR is supported by the ETH Zurich Foundation, in collaboration with Coop (ETH Research Grant 1014-1). We acknowledge ECMWF and NOAA for providing the ERA-Interim reanalysis dataset available from http://www.ecmwf.int and the IBTrACS dataset available from https:// www.ncdc.noaa.gov/ibtracs/. We are grateful to three reviewers who provided thoughtful and precise comments, which helped to significantly improve the content and clarity of the manuscript.

\section{REFERENCES}

Agustí-Panareda, A., 2008: The contribution of Ex-Tropical Cyclone Gert (1999) toward the weakening of a midlatitude cyclogenesis event. Mon. Wea. Rev., 136, 2091-2111, https://doi.org/10.1175/ 2007MWR1637.1.

— C. D. Thorncroft, G. C. Craig, and S. L. Gray, 2004: The extratropical transition of Hurricane Irene (1999): A potential-vorticity perspective. Quart. J. Roy. Meteor. Soc., 130, 1047-1074, https://doi.org/10.1256/qj.02.140.

—, S. L. Gray, G. C. Craig, and C. Thorncroft, 2005: The extratropical transition of Tropical Cyclone Lili (1996) and its crucial contribution to a moderate extratropical development. Mon. Wea. Rev., 133, 1562-1573, https://doi.org/10.1175/ MWR2935.1.

Aiyyer, A., 2015: Recurving western North Pacific tropical cyclones and midlatitude predictability. Geophys. Res. Lett., 42, 7799-7807, https://doi.org/10.1002/2015GL065082.

Anwender, D., P. A. Harr, and S. C. Jones, 2008: Predictability associated with the downstream impacts of the extratropical transition of tropical cyclones: Case studies. Mon. Wea. Rev., 136, 3226-3247, https://doi.org/10.1175/2008MWR2249.1.

Archambault, H. M., L. F. Bosart, D. Keyser, and J. M. Cordeira, 2013: A climatological analysis of the extratropical flow response to recurving western North Pacific tropical cyclones. Mon. Wea. Rev., 141, 2325-2346, https://doi.org/10.1175/ MWR-D-12-00257.1.

— D. Keyser, L. F. Bosart, C. A. Davis, and J. M. Cordeira, 2015: A composite perspective of the extratropical flow response to recurving western North Pacific tropical cyclones. Mon. Wea. Rev., 143, 1122-1141, https://doi.org/10.1175/MWR-D-14-00270.1.

Atallah, E. H., and L. F. Bosart, 2003: The extratropical transition and precipitation distribution of Hurricane Floyd (1999). Mon. Wea. Rev., 131, 1063-1081, https://doi.org/10.1175/15200493(2003)131<1063:TETAPD>2.0.CO;2.

Barton, Y., P. Giannakaki, H. von Waldow, C. Chevalier, S. Pfahl, and O. Martius, 2016: Clustering of regional-scale extreme precipitation events in southern Switzerland. Mon. Wea. Rev., 144, 347-369, https://doi.org/10.1175/MWR-D-15-0205.1.

Chang, E. K. M., and D. B. Yu, 1999: Characteristics of wave packets in the upper troposphere. Part I: Northern
Hemisphere winter. J. Atmos. Sci., 56, 1708-1728, https://doi.org/ 10.1175/1520-0469(1999)056<1708:COWPIT>2.0.CO;2.

Cordeira, J. M., F. M. Ralph, and B. J. Moore, 2013: The development and evolution of two atmospheric rivers in proximity to western North Pacific tropical cyclones in October 2010. Mon. Wea. Rev., 141, 4234-4255, https://doi.org/10.1175/ MWR-D-13-00019.1.

Dacre, H. F., P. A. Clark, O. Martinez-Alvarado, M. A. Stringer, and D. A. Lavers, 2015: How do atmospheric rivers form? Bull. Amer. Meteor. Soc., 96, 1243-1255, https://doi.org/ 10.1175/BAMS-D-14-00031.1.

Dee, D. P., and Coauthors, 2011: The ERA-Interim reanalysis: Configuration and performance of the data assimilation system. Quart. J. Roy. Meteor. Soc., 137, 553-597, https://doi.org/ 10.1002/qj.828.

Evans, C., and Coauthors, 2017: The extratropical transition of tropical cyclones. Part I: Cyclone evolution and direct impacts. Mon. Wea. Rev., 145, 4317-4344, https://doi.org/10.1175/ MWR-D-17-0027.1.

Giannakaki, P., and O. Martius, 2016: Synoptic-scale flow structures associated with extreme precipitation events in northern Switzerland. Int. J. Climatol., 36, 2497-2515, https://doi.org/ $10.1002 /$ joc. 4508 .

Grams, C. M., and S. R. Blumer, 2015: European high-impact weather caused by the downstream response to the extratropical transition of North Atlantic Hurricane Katia (2011). Geophys. Res. Lett., 42, 8738-8748, https://doi.org/10.1002/ 2015 GL066253.

_ , and H. M. Archambault, 2016: The key role of diabatic outflow in amplifying the midlatitude flow: A representative case study of weather systems surrounding western North Pacific extratropical transition. Mon. Wea. Rev., 144, 3847-3869, https://doi.org/10.1175/MWR-D-15-0419.1.

— S. C. Jones, C. A. Davis, P. A. Harr, and M. Weissmann, 2013: The impact of Typhoon Jangmi (2008) on the midlatitude flow. Part I: Upper-level ridgebuilding and modification of the jet. Quart. J. Roy. Meteor. Soc., 139, 2148-2164, https://doi.org/ 10.1002/qj.2091.

—, S. T. K. Lang, and J. H. Keller, 2015: A quantitative assessment of the sensitivity of the downstream midlatitude flow response to extratropical transition of tropical cyclones. Geophys. Res. Lett., 42, 9521-9529, https://doi.org/10.1002/ 2015 GL065764.

— , and Coauthors, 2011: The key role of diabatic processes in modifying the upper-tropospheric wave guide: A North Atlantic case-study. Quart. J. Roy. Meteor. Soc., 137, 2174-2193, https://doi.org/10.1002/qj.891.

Hardy, S., D. M. Schultz, and G. Vaughan, 2017: The 23-26 September 2012 U.K. floods: Using PV surgery to quantify sensitivity to upperlevel forcing. Mon. Wea. Rev., 145, 4055-4079, https://doi.org/ 10.1175/MWR-D-16-0434.1.

Harr, P. A., and H. M. Archambault, 2016: Dynamics, predictability, and high-impact weather associated with the extratropical transition of tropical cyclones. Dynamics and Predictability of Large-Scale, High-Impact Weather and Climate Events, J. Li et al., Eds., Cambridge University Press, 153-167, https:// doi.org/10.1017/CBO9781107775541.

Hart, R. E., and J. L. Evans, 2001: A climatology of the extratropical transition of Atlantic tropical cyclones. J. Climate, 14, 546-564, https://doi.org/10.1175/1520-0442(2001)014<0546:ACOTET> 2.0.CO;2.

Jones, S. C., and Coauthors, 2003: The extratropical transition of tropical cyclones: Forecast challenges, current understanding, 
and future directions. Wea. Forecasting, 18, 1052-1092, https:// doi.org/10.1175/1520-0434(2003)018<1052:TETOTC > 2.0.CO;2.

Keller, J. H., S. C. Jones, J. L. Evans, and P. A. Harr, 2011: Characteristics of the TIGGE multimodel ensemble prediction system in representing forecast variability associated with extratropical transition. Geophys. Res. Lett., 38, L12802, https://doi.org/10.1029/2011GL047275.

,$- \ldots$, and P. A. Harr, 2014: An eddy kinetic energy view of physical and dynamical processes in distinct forecast scenarios for the extratropical transition of two tropical cyclones. Mon. Wea. Rev., 142, 2751-2771, https://doi.org/10.1175/MWR-D13-00219.1.

- and Coauthors, 2019: The extratropical transition of tropical cyclones. Part II: Interaction with the midlatitude flow, downstream impacts, and implications for predictability. Mon. Wea. Rev., 147, 1077-1106, https://doi.org/10.1175/MWR-D17-0329.1.

Knapp, K. R., M. C. Kruk, D. H. Levinson, H. J. Diamond, and C. J. Neumann, 2010: The International Best Track Archive for Climate Stewardship (IBTrACS). Bull. Amer. Meteor. Soc., 91, 363-376, https://doi.org/10.1175/2009BAMS2755.1.

Lavers, D. A., G. Villarini, R. P. Allan, E. F. Wood, and A. J. Wade, 2012: The detection of atmospheric rivers in atmospheric reanalyses and their links to British winter floods and the large-scale climatic circulation. J. Geophys. Res., 117, D20106, https://doi.org/10.1029/2012JD018027.

Liu, M., G. A. Vecchi, J. A. Smith, and H. Murakami, 2017: The present-day simulation and twenty-first-century projection of the climatology of extratropical transition in the North Atlantic. J. Climate, 30, 2739-2756, https://doi.org/10.1175/ JCLI-D-16-0352.1.

Martius, O., C. Schwierz, and H. C. Davies, 2008: Far-upstream precursors of heavy precipitation events on the Alpine southside. Quart. J. Roy. Meteor. Soc., 134, 417-428, https://doi.org/ 10.1002/qj.229.

——, —, and ——, 2010: Tropopause-level waveguides. J. Atmos. Sci., 67, 866-879, https://doi.org/10.1175/ 2009JAS2995.1.

Massacand, A. C., H. Wernli, and H. C. Davies, 2001: Influence of upstream diabatic heating upon an Alpine event of heavy precipitation. Mon. Wea. Rev., 129, 2822-2828, https://doi.org/ 10.1175/1520-0493(2001)129<2822:IOUDHU>2.0.CO;2.

McTaggart-Cowan, R., J. R. Gyakum, and M. K. Yau, 2001: Sensitivity testing of extratropical transitions using potential vorticity inversions to modify initial conditions: Hurricane Earl case study. Mon. Wea. Rev., 129, 1617-1636, https://doi.org/ 10.1175/1520-0493(2001)129<1617:STOETU >2.0.CO;2.

,-- , and $—$ 2003: The influence of the downstream state on extratropical transition: Hurricane Earl (1998) case study. Mon. Wea. Rev., 131, 1910-1929, https://doi.org/10.1175// 2589.1.

_ L. F. Bosart, J. R. Gyakum, and E. H. Atallah, 2007: Hurricane Katrina (2005). Part II: Evolution and hemispheric impacts of a diabatically generated warm pool. Mon. Wea. Rev. 135, 3927-3949, https://doi.org/10.1175/2007MWR2096.1.

Nuissier, O., V. Ducrocq, D. Ricard, C. Lebeaupin, and S. Anquetin, 2008: A numerical study of three catastrophic precipitating events over southern France. I: Numerical framework and synoptic ingredients. Quart. J. Roy. Meteor. Soc., 134, 111-130, https://doi.org/10.1002/qj.200.

Pantillon, F., J.-P. Chaboureau, P. J. Mascart, and C. Lac, 2013: Predictability of a Mediterranean tropica-like storm downstream of the extratropical transition of Hurricane Helene
(2006). Mon. Wea. Rev., 141, 1943-1962, https://doi.org/ 10.1175/MWR-D-12-00164.1.

- — - and E. Richard, 2015: Remote impact of North Atlantic hurricanes on the Mediterranean during episodes of intense rainfall in autumn 2012. Quart. J. Roy. Meteor. Soc., 141, 967-978, https://doi.org/10.1002/qj.2419.

Pfahl, S., and H. Wernli, 2012: Quantifying the relevance of cyclones for precipitation extremes. J. Climate, 25, 6770-6780, https://doi.org/10.1175/JCLI-D-11-00705.1.

Piaget, N., P. Froidevaux, P. Giannakaki, F. Gierth, O. Martius, M. Riemer, G. Wolf, and C. M. Grams, 2015: Dynamics of a local Alpine flooding event in October 2011: Moisture source and large-scale circulation. Quart. J. Roy. Meteor. Soc., 141, 1922-1937, https://doi.org/10.1002/qj.2496.

Pinto, J. G., M. Klawa, U. Ulbrich, R. Rudari, and P. Speth, 2001: Extreme precipitation events over Northwest Italy and their relationship with tropical-extratropical interactions over the Atlantic. Proc. Third EGS Plinius Conf. on Mediterranean Storms, Vol. 118, Baja Sardinia, Italy, Consiglio Nazionale delle Ricerche, 2085-2097.

Pohorsky, R., 2017: A climatological analysis of downstream precipitation extremes associated with recurving North Atlantic tropical cyclones. M.S. thesis, Institute of Geography, University of Bern, $83 \mathrm{pp}$.

Quinting, J. F., and S. C. Jones, 2016: On the impact of tropical cyclones on Rossby wave packets: A climatological perspective. Mon. Wea. Rev., 144, 2021-2048, https://doi.org/10.1175/ MWR-D-14-00298.1.

Riboldi, J., M. Röthlisberger, and C. M. Grams, 2018: Rossby wave initiation by recurving tropical cyclones in the western North Pacific. Mon. Wea. Rev., 146, 1283-1301, https://doi.org/ 10.1175/MWR-D-17-0219.1.

Riemer, M., and S. C. Jones, 2010: The downstream impact of tropical cyclones on a developing baroclinic wave in idealized scenarios of extratropical transition. Quart. J. Roy. Meteor. Soc., 136, 617-637, https://doi.org/10.1002/qj.605.

$\longrightarrow$, and — 2014: Interaction of a tropical cyclone with a highamplitude, midlatitude wave pattern: Waviness analysis, trough deformation and track bifurcation. Quart. J. Roy. Meteor. Soc., 140, 1362-1376, https://doi.org/10.1002/qj.2221.

,- , and C. A. Davis, 2008: The impact of extratropical transition on the downstream flow: An idealized modelling study with a straight jet. Quart. J. Roy. Meteor. Soc., 134, 69-91, https://doi.org/10.1002/qj.189.

Ritchie, E. A., and R. L. Elsberry, 2001: Simulations of the transformation stage of the extratropical transition of tropical cyclones. Mon. Wea. Rev., 129, 1462-1480, https://doi.org/ 10.1175/1520-0493(2001)129<1462:SOTTSO > 2.0.CO;2. , and - 2003: Simulations of the extratropical transition of tropical cyclones: Contributions by the midlatitude upper-level trough to reintensification. Mon. Wea. Rev., 131, 2112-2128, https://doi.org/10.1175/1520-0493(2003)131<2112: SOTETO $>2.0 . \mathrm{CO} ; 2$

, and - 2007: Simulations of the extratropical transition of tropical cyclones: Phasing between the upper-level trough and tropical cyclones. Mon. Wea. Rev., 135, 862-876, https://doi.org/ 10.1175/MWR3303.1.

Romero, R., J. A. Guijarro, C. Ramis, and S. Alonso, 1998: A 30-year (1964-1993) daily rainfall data base for the Spanish Mediterranean regions: First exploratory study. Int. J. Climatol., 18, 541-560, https://doi.org/10.1002/(SICI)1097-0088(199804)18: $5<541::$ AID-JOC270>3.0.CO;2-N

Röthlisberger, M., O. Martius, and H. Wernli, 2016a: An algorithm for identifying the initiation of synoptic-scale Rossby waves on 
potential vorticity waveguides. Quart. J. Roy. Meteor. Soc., 142, 889-900, https://doi.org/10.1002/qj.2690.

, S. Pfahl, and O. Martius, 2016b: Regional-scale jet waviness modulates the occurrence of midlatitude weather extremes. Geophys. Res. Lett., 43, 10 989-10 997, https://doi.org/10.1002/ 2016GL070944.

, O. Martius, and H. Wernli, 2018: Northern Hemisphere Rossby wave initiation events on the extratropical jet-A climatological analysis. J. Climate, 31, 743-760, https://doi.org/ 10.1175/JCLI-D-17-0346.1.

Toreti, A., P. Giannakaki, and O. Martius, 2016: Precipitation extremes in the Mediterranean region and associated upper-level synoptic-scale flow structures. Climate Dyn., 47, 1925-1941, https://doi.org/10.1007/s00382-015-2942-1.

Torn, R. D., and G. J. Hakim, 2015: Comparison of wave packets associated with extratropical transition and winter cyclones. Mon. Wea. Rev., 143, 1782-1803, https://doi.org/10.1175/ MWR-D-14-00006.1.

Wilks, D. S., 2006: Statistical Methods in the Atmospheric Sciences. Elsevier Inc., $627 \mathrm{pp}$.

Wirth, V., M. Riemer, E. K. M. Chang, and O. Martius, 2018: Rossby wave packets on the midlatitude waveguide-A review. Mon. Wea. Rev., 146, 1965-2001, https://doi.org/10.1175/ MWR-D-16-0483.1. 